Check for updates

Cite this: Mater. Adv., 2021, 2, 4165

Received 23rd March 2021, Accepted 24th May 2021

DOI: $10.1039 / \mathrm{d} 1 \mathrm{ma} 00247 \mathrm{c}$

rsc.li/materials-advances

\section{Unveiling the physiochemical aspects of the matrix in improving sulfur-loading for room-temperature sodium-sulfur batteries}

\author{
Sungjemmenla, Chhail Bihari Soni, S. K. Vineeth and Vipin Kumar (D)*
}

\begin{abstract}
The sulfur cathode in $\mathrm{Na} / \mathrm{S}$ batteries possesses a very high theoretical specific capacity of about $1675 \mathrm{~mA} \mathrm{~h} \mathrm{~g}^{-1}$ and specific energy of $1230 \mathrm{~W} \mathrm{~h} \mathrm{~kg}^{-1}$ (which is over five times that of the $\mathrm{LiCoO}_{2}$ cathode in Li-ion batteries), besides high abundance and cost-effectiveness of the electrode materials. The sulfur cathode in $\mathrm{Na} / \mathrm{S}$ batteries undergoes various electrochemical processes, where a series of soluble sodium polysulfides are formed during the discharge reaction, which adversely affects the operation of the cell. Furthermore, the viable application of RT-Na/S batteries is severely challenged by various obstacles, including their short-life and low-sulfur utilization, which become more serious when sulfur loading is increased to the practically acceptable level of over $5 \mathrm{mg} \mathrm{cm}^{-2}$. Thus, there have been innovative efforts in recent years to manipulate the physiochemistry of the matrix to overcome these barriers toward the practical application of RT-Na/S batteries with an improved sulfur loading close to practical limits. The rational design of the matrix (i.e., physicochemical aspects) with a high-sulfur utilization and long lifespan are two crucial challenges that $\mathrm{Na} / \mathrm{S}$ batteries are experiencing currently and require immediate attention to be addressed. This review highlights the recent progress on tuning the physiochemistry of the matrix through chemical and physical means to realize an improved sulfur-loading. Particularly, basic insight into the chemical binding, strategies for mesoscale assembly, unique architectures, and configurational innovation in the cathode are the specific focus. Finally, novel strategies to improve sulfur-loading are proposed to guide the future development of high-sulfur loading RT-Na/S batteries.
\end{abstract}

\section{Introduction}

There is growing interest in high-energy rechargeable batteries for large-scale stationary energy storage. ${ }^{1-3}$ Rechargeable lithiumion batteries with an energy density of about $180 \mathrm{~W} \mathrm{~h} \mathrm{~kg}^{-1}$ are still the first choice for portable and mobile applications, but the high cost of Li-ion batteries per kWh limits their use in stationary storage applications. ${ }^{3-8}$ Besides, the performance of Li-ion batteries has plateaued due to the fundamental limitations of the electrode materials.

Recently, interest in sodium-sulfur batteries has been revived due to their unique attributes, including high theoretical specific capacity and energy density, high natural abundance and longterm sustainability. ${ }^{9}$ In addition, sodium-sulfur electrochemistry offers several other advantages, such as (1) stable-operation, (2) minimal self-discharge, (3) low-cost per cycle, (4) high energy efficiency, and (5) non-toxicity. ${ }^{10}$ Significant progress has been made in high-temperature sodium-sulfur (HT-Na/S) battery technology

Centre for Energy Studies (CES), Indian Institute of Technology Delhi, Hauz Khas, New Delhi, Delhi, 110016, India.E-mail:vkumar@ces.iitd.ac.in owing to its high theoretical energy density (760 $\mathrm{W} \mathrm{h} \mathrm{kg}^{-1}$ ) and power capability with excellent durability for over 15 years or 2500 cycles. ${ }^{11}$ HT-Na/S batteries as cutting-edge technology have found applications in space, electric vehicles grid storage, and aeronautics. ${ }^{12,13}$ Attempts have been made to utilize HT-Na/S batteries for large-scale grid storage applications. For instance, Kawakami and coworkers stabilized the fluctuating wind power of about 51 MW using a 34 MW HT-Na/S battery system in Japan. ${ }^{14}$ Similarly, other groups used HT-Na/S batteries for matured over time and been well constructed and developed mainly for large-scale storage applications. However, despite these achievements, HT-Na/S is severely compromised regarding safety due to its high operating temperatures $\left(>300{ }^{\circ} \mathrm{C}\right)$, which are required to achieve the desired ionic conductivity of the solidelectrolyte. In addition, the reaction between molten sulfur and sodium can liberate a high enthalpy of about $-420 \mathrm{~kJ} \mathrm{~mol}^{-1}$, which may further contribute to an increase in the cell temperature. ${ }^{16}$ Thus, the high operating temperature $\left(300-350{ }^{\circ} \mathrm{C}\right)$, high initial cost, corrosivity and low Coulombic efficiency of HT-Na/S batteries challenge their long-term viability. load-leveling in wind-farms. ${ }^{15}$ HT-Na/S battery technology has 
In contrast to the HT-Na/S battery, the room-temperature sodium-sulfur (RT-Na/S) battery offers a safe and reliable operation with a low operating cost, ${ }^{17-19}$ delivering a remarkably high theoretical specific energy of $\sim 1230 \mathrm{~W} \mathrm{~h} \mathrm{~kg}{ }^{-1} \cdot{ }^{20}$ Park and co-workers proposed the idea of developing a room-temperature analogue instead, which consists of a solid form of both sodium and sulfur electrodes. ${ }^{21}$ This battery delivered an initial discharge capacity of about $489 \mathrm{~mA} \mathrm{~h} \mathrm{~g}^{-1}$; however, it could only be cycled for 20 cycles with a drastic decrease (nearly tenfold) in its reversible capacity. Wang et al. ${ }^{22}$ investigated for the first time the use of a conductive polymer-PAN/S as the cathode material for RT-Na/S to enhance both the cycling stability and performance of the cell. The hybrid composite sulfur cathode exhibited an improved performance of about $655 \mathrm{~mA} \mathrm{~h} \mathrm{~g}{ }^{-1}$; however, the cell was plagued with a low cycle-life (only for 18 cycles), while it retained a reversible capacity of about $500 \mathrm{~mA} \mathrm{~h} \mathrm{~g}^{-1}$. Subsequently, significant progress has been made in the development of state-of-the-art composite cathodes with remarkable progress in the rate capability and ultra-long cycle-life. ${ }^{23,24}$ Recently, attempts have been made to understand the charging/discharging mechanism in $\mathrm{Na} / \mathrm{S}$ batteries via both experiment and theoretical modeling. Although the intermediate reactions are very complex, the generally accepted discharging reaction in the RT-Na/S battery follows $\mathrm{S}_{8} \rightarrow \mathrm{Na}_{2} \mathrm{~S}_{8} \rightarrow \mathrm{Na}_{2} \mathrm{~S}_{6} \rightarrow \mathrm{Na}_{2} \mathrm{~S}_{4} \rightarrow \mathrm{Na}_{2} \mathrm{~S}_{2} \rightarrow \mathrm{Na}_{2} \mathrm{~S}$, where the long-chain polysulfides, i.e., $\mathrm{Na}_{2} \mathrm{~S}_{8}$ and $\mathrm{Na}_{2} \mathrm{~S}_{6}$, readily dissolve in the electrolyte. ${ }^{25}$ In most cases, the dissolved polysulfides move towards the anode (i.e., shutting effect) and hamper the anode operation permanently, leading to rapid capacity fading and poor cycling stability. ${ }^{26,27}$ Polysulfide cross-over or shuttling can be evaded partly through physical or chemical trapping by the matrix, i.e., carbon scaffold, in most cases. ${ }^{28}$ Extensive research efforts have been focused on finding better matrix materials that can offer great absorption sites for the long-chain polysulfides to bind without compromising with electronic conductivity of the electrode materials. However, the key challenge with this technology is the low sulfur loading, which lowers its capacity and the overall specific energy.

Although good progress in the electrochemistry of cathode composites has been achieved in recent years, the low sulfur loading, which is below $3 \mathrm{mg} \mathrm{cm}^{-2}$, eventually hinders the cell from reaching its unprecedented theoretical value. Furthermore, when attempts were made to improve the sulfur loading in the cathode, the performance of the cell was observed to deteriorate rapidly due to the lack of efficient binding sites, strong inter-particle interaction, and optimized ratio of electrolyte and sulfur (i.e., E/S). ${ }^{29}$ Thus, to achieve a high specific energy, it is urgent to increase the loading $\left(>3 \mathrm{mg} \mathrm{cm}^{-2}\right)$ and weight percentage of sulfur. ${ }^{30}$ Pope et al. reported different cathode architectures for $\mathrm{Li} / \mathrm{S}$ batteries, where they analyzed the specific energy as a function of the sulfur loading. ${ }^{31}$ They identified that a higher specific energy of about $400 \mathrm{~W} \mathrm{~h} \mathrm{~kg} \mathrm{~g}^{-1}$ could be achieved with sulfur loadings greater than $2 \mathrm{mg} \mathrm{cm}^{-2}$. It is evident that an increase in the sulfur loading has a profound impact on the practicality of metal-sulfur battery systems. Several research groups have presented impactful reviews on the $\mathrm{Na}-\mathrm{S}$ battery; $;^{32-35}$ however, this mini-review introduces the key issues and different aspects of the matrix towards the development of a high loading sulfur cathode for RT-Na/S batteries. Particularly, the recent advances with a judicious combination of different composite materials and representative physical and chemical aspects of cathode engineering are summarized, as schematically depicted in Fig. 1. In addition, novel strategies to improve the sulfur loading are proposed to guide the future development of high-sulfur-loading sulfur cathodes for RT-Na/S batteries.

\section{The physio-chemistry of the matrix for sulfur cathodes}

A room-temperature $\mathrm{Na}-\mathrm{S}$ battery is comprised of a sulfur cathode, sodium metal anode, and a separator soaked in a liquid electrolyte, as depicted schematically in Fig. 2. The sulfur cathode, which consists of elemental sulfur particles, binder, and conductive filler, undergoes severe chemical and structural changes during the charge/discharge reactions. The chemical and physical changes that occur in the matrix mainly dictate the stability of the sulfur cathode and kinetics of the conversion reactions. Although the charge/discharge reactions are very

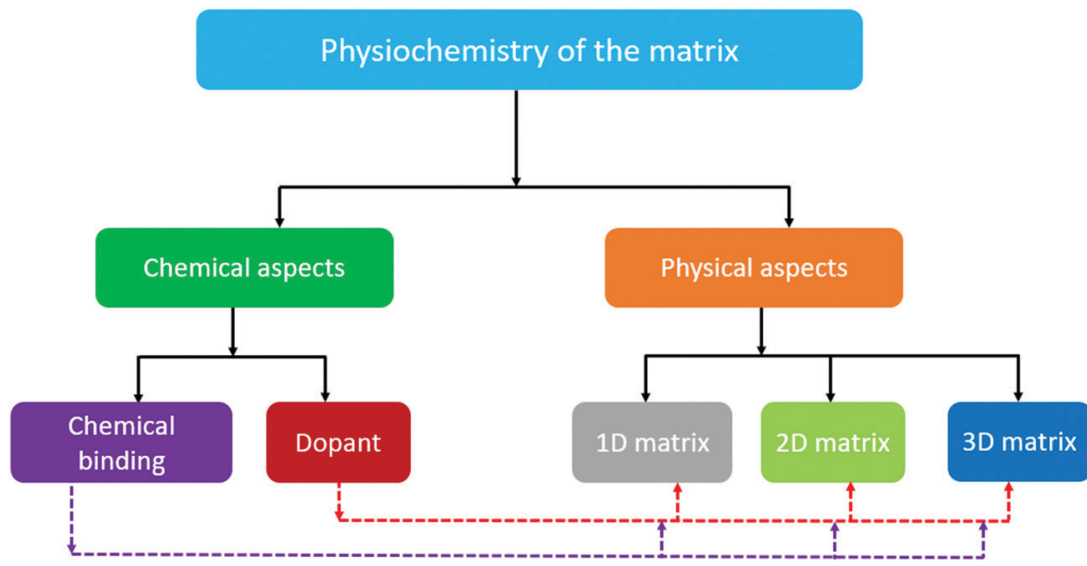

Fig. 1 Schematic illustration of the rational design of the matrix for high-loading sulfur cathodes for RT/Na-S batteries. 


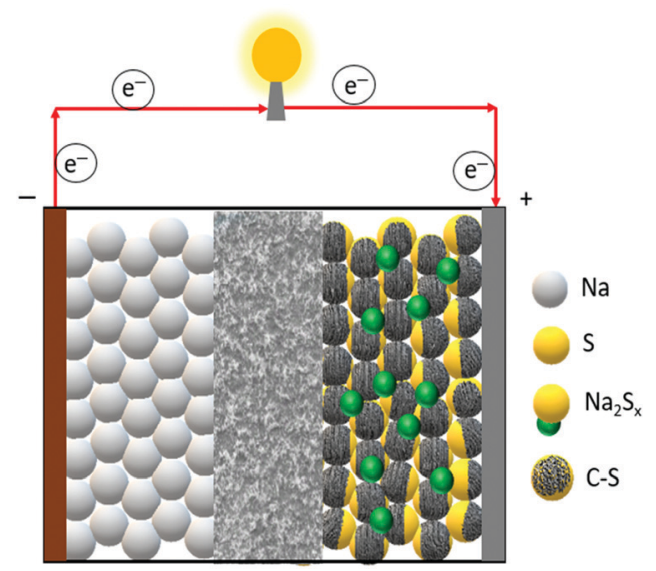

Fig. 2 Schematic representation of an RT-Na/S battery.

complicated, the intermediate reaction steps that occur during the reactions are presented below through a series of reactions (eqn (1)-(4)). ${ }^{34,36}$

$$
\begin{aligned}
\mathrm{S}_{8}+2 \mathrm{Na}^{+}+2 \mathrm{e}^{-} & \rightarrow \mathrm{Na}_{2} \mathrm{~S}_{8} \quad \text { (solid-liquid transition; } \\
& \sim 2.20 \mathrm{~V} \text { vs. } \mathrm{Na} / \mathrm{Na}^{+} \text {) }
\end{aligned}
$$

$$
\mathrm{Na}_{2} \mathrm{~S}_{8}+2 \mathrm{Na}^{+}+2 \mathrm{e}^{-} \rightarrow 2 \mathrm{Na}_{2} \mathrm{~S}_{4} \quad \text { (liquid-liquid transition; }
$$$$
\text { 2.20-1.65 V vs. } \mathrm{Na} / \mathrm{Na}^{+} \text {) }
$$

$$
\mathrm{Na}_{2} \mathrm{~S}_{4}+\frac{2}{3} \mathrm{Na}^{+}+\frac{2}{3} \mathrm{e}^{-} \rightarrow \frac{4}{3} \mathrm{Na}_{2} \mathrm{~S}_{3}
$$$$
\text { (liquid-solid transition; } \sim 1.65 \mathrm{~V} v s . \mathrm{Na} / \mathrm{Na}^{+} \text {) }
$$$$
\mathrm{Na}_{2} \mathrm{~S}_{4}+2 \mathrm{Na}^{+}+2 \mathrm{e}^{-} \rightarrow 2 \mathrm{Na}_{2} \mathrm{~S}_{2}
$$$$
\mathrm{Na}_{2} \mathrm{~S}_{4}+6 \mathrm{Na}^{+}+6 \mathrm{e}^{-} \rightarrow 4 \mathrm{Na}_{2} \mathrm{~S}
$$

$$
\mathrm{Na}_{2} \mathrm{~S}_{2}+2 \mathrm{Na}^{+}+2 \mathrm{e}^{-} \rightarrow 2 \mathrm{Na}_{2} \mathrm{~S} \quad \text { (solid-solid transition; }
$$

$$
\text { 1.65-1.20 V vs. } \mathrm{Na} / \mathrm{Na}^{+} \text {) }
$$

The overall reaction during the discharge process can be expressed as:

$$
\begin{gathered}
\text { Anode: } 2 \mathrm{Na} \rightarrow 2 \mathrm{Na}^{+}+2 \mathrm{e}^{-} \\
\text {Cathode: } 1 / 8 \mathrm{~S}_{8}+2 \mathrm{Na}^{+}+2 \mathrm{e}^{-} \rightarrow \mathrm{Na}_{2} \mathrm{~S}
\end{gathered}
$$

The reduction of $\mathrm{Na}^{+}$ions occurs at the cathode, where sulfur gains electrons and combines with the sodium ions to produce a range of polysulfides $\left(\mathrm{Na}_{2} \mathrm{~S}_{n}\right)$, ranging from long-chain $(4 \leq$ $n \leq 8)$ to short-chain polysulfides $(1 \leq n \leq 4) .{ }^{36}$ The dissolution and diffusion of sodium polysulfides upon the oxidation of $\mathrm{Na}_{2} \mathrm{~S}_{x}(x=1)$ provide mediators for the redox reactions to enhance the insulating nature of the elemental sulfur $(5 \times$ $10^{-30} \mathrm{~S} \mathrm{~cm}^{-1}$ @25 ${ }^{\circ} \mathrm{C}$ ) and $\mathrm{Na}_{2} \mathrm{~S} .{ }^{35,37}$ Due to the high solubility of the reaction intermediates, they shuttle between the anode and cathode, leading to polysulfide shuttling. The shuttle effect for RT-Na/S is even more severe than that of the Li-S battery, and consequently large volume fluctuations (about 170\%) occur, leading to the structural collapse of the cathode during repeated charge/discharge cycles. ${ }^{38-41}$ The aforementioned issues primarily restrict the proper utilization of sulfur materials and mainly contribute to the low specific energy of RT-Na/S. ${ }^{42}$ With an increase in the sulfur loading, the performance of the battery deteriorates even faster due to the limited diffusion of sodium ions and low accessibility of the electrolyte. All these factors severely affect the battery performance (including low Coulombic efficiency, selfdischarge, loss of sulfur and its dissociated products, and fast fading rate $^{41}$ ) and hamper the further development of RT-Na/S batteries. Therefore, the rational design of the matrix materials, which can overcome the aforementioned issues, is crucial to realize the practical use of RT-Na/S batteries.

\subsection{Chemical aspects}

The sulfur cathode contributes two electrons to the reaction and offers a high theoretical capacity of about $1675 \mathrm{~mA} \mathrm{~h} \mathrm{~g}{ }^{-1} \cdot{ }^{43}$ However, it is immensely challenging to extract the theoretical capacity from sulfur cathode due to two major challenges. Firstly, the dissolution of high-order polysulfide intermediates $\left(\mathrm{Na}_{2} \mathrm{~S}_{8}-\right.$ $\mathrm{Na}_{2} \mathrm{~S}_{4}$, i.e., long-chain polysulfides) in organic electrolytes causes severe sulfur loss in the cathode, reducing the cycle-life of RT-Na/S. The dissolution of the high-order polysulfides also requires a flooded electrolyte (FE) to achieve a high power density, sacrificing the total energy density. Secondly, Na plating/stripping continuously consumes the Na-metal anode and electrolyte during cycling, which requires excess Na-metal and electrolyte, thus further reducing the Coulombic efficiency and energy density of RT-Na/S.

To date, numerous strategies and different material chemistries have been developed to modify the matrix (i.e., sulfur host) and minimize dissolution of sodium polysulfides. To promote the kinetics of the conversion reactions, a chemically modified sulfur matrix has been demonstrated as a potential solution to enhance the performance of RT-Na/S batteries.

2.1.1 Chemical binding. The poor ionic and electronic conductivity of the elemental sulfur cathode can be greatly improved through chemical modification of the sulfur matrix. The approach that has been investigated for improving the electronic conductivity is based on the coating technique, ${ }^{44,45}$ which mainly involves coating a thin polymeric material to promote the inter-particle contact and chemical trapping of the dissolved intermediate sodium polysulfides. ${ }^{46,47}$ Attempts have been made to design and develop various matrices with diverse chemical structures and morphologies, ${ }^{48}$ which have significantly improved the stability of the sulfur cathode during the charge/discharge reactions. However, the chemically modified structure could not prevent capacity fading during cycling, which may likely be due to the weak interparticle chemical interaction within the electrode materials. It is noteworthy that the chemical coating alters the chemical structure of the matrix, but most polymer coatings examined to date do not establish good chemical interaction with the sulfur particles. Given that the weak interactions can be easily broken upon high-volume changes during cycling, it is nearly impossible to prohibit capacity fading using the chemically modified matrix approach. ${ }^{49-51}$

The other aspect that can be employed is to use binders to alter the chemical functionality of the matrix instead of polymeric coatings. The chemically altered binder approach greatly improves 
the structural integrity of the cathode. ${ }^{52-54}$ Although the binder accounts for only about 2 to $10 \mathrm{wt} \%$ of the overall electrode material, it plays a critical role in ensuring the stable performance of batteries. The primary function of a chemical binder is to provide (i) strong inter-particle adhesion and binding, (ii) abundant adsorption sites to adsorb or absorb the discharge products, and (iii) a robust and interconnected structure to prevent pulverization of the cathode material during volumetric contraction/ expansion during the charge/discharge reactions. ${ }^{55-57}$ Traditionally, linear binders, such as poly(vinylidene-fluoride) (PVDF), have been used to form cathode films for RT-Na/S batteries. The polar groups (i.e., $-\mathrm{CF}_{2}$ ) of the PVDF binder molecules facilitate the adhesion among various components of the cathode, which include sulfur particles, conductive fillers, and the current collector. In addition, the van der Waals forces among the polymer chains provide good elasticity to accommodate the volume change upon repeated discharge/charge cycles. It is important to note that the volume change in the sulfur cathode is many times that of the conventional oxide cathode, ${ }^{40,58}$ and thus the PVDF binder encounters a significant challenge in ensuring long-term stability of the cathode, especially when the sulfur loading is high or close to the practical limits. Accordingly, by altering the molecular structure and surface chemistry of the binder molecules, researchers can explore alternative binders to promote better mechanical properties. ${ }^{59,60}$ Polar functional groups, for instance, $-\mathrm{OH}$, and $-\mathrm{COOH}$, have been incorporated to form covalent bonds with $\mathrm{S}-\mathrm{C}$ composites and the substrate. Recently, Alex and co-workers tailored the binder interactions with the cathode materials through $-\mathrm{COOH}$ functional groups to gain a better perspective towards binder assembly. ${ }^{54}$ Carboxyl-containing binders were utilized as an alternative to the traditional PVDF binder due to the relatively stronger interaction of their polar groups with sodium polysulfide. Polyacrylic acid (PAA) binder, which behaves as a trap for the soluble sodium polysulfides during the sodiation cycles, can readily adsorb sodium polysulfide. The adsorption of sodium polysulfide was validated through theoretical calculations. For example, the binding energy of $\mathrm{Na}_{2} \mathrm{~S}$ for PAA binder is about $2.02 \mathrm{eV}$, which is nearly $60 \%$ that of the PVDF binder (binding energy of about $1.20 \mathrm{eV}$ ). Scanning electron microscopy (SEM) images revealed the uniform particle distribution on the cathode surface for a PAA-based sulfur cathode, whereas the PVDF-based cathode contained large fractures and showed lower contrast due to the passivation layer on its surface (see Fig. 3a-d). As schematically illustrated in Fig. 3e, a conjugated pyridine-like backbone confirms the cyclization in forming strong interactions between $\mathrm{C}=\mathrm{C}$ and $\mathrm{C}=\mathrm{N}$ bonds. The strong bonds formed with the carboxyl groups potentially act as a chemical trap if discharge products are inadvertently formed during sodiation. Consequently, due to these strong interactions, a sulfur content as high as $41 \mathrm{wt} \%$ could be achieved and the mass loading of the active material could reach about $1.8 \mathrm{mg} \mathrm{cm}^{-2}$. Due to the locally modified matrix structure, the rate capability tests showed high specific capacity values for the PAA-based cathodes of $1023 \mathrm{~mA} \mathrm{~h} \mathrm{~g}^{-1}$, $920 \mathrm{~mA} \mathrm{~h} \mathrm{~g}^{-1}$ and $800 \mathrm{~mA} \mathrm{~h} \mathrm{~g}{ }^{-1}$ at 1C, 2C and 4C, respectively. In contrast, the PVDF based cathode exhibited a much lower specific capacity of $554 \mathrm{~mA} \mathrm{~h} \mathrm{~g}^{-1}$ at a C-rate of $4 \mathrm{C}$.

Besides PAA, a hybrid sodium alginate-polyaniline matrix binder was also developed and observed to play a crucial role due to its inherent stiffness and swelling properties. ${ }^{61}$ In contrast to the conventional binder (see Fig. 3f), sodium alginate could preserve

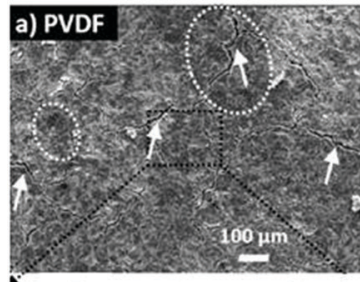

e)

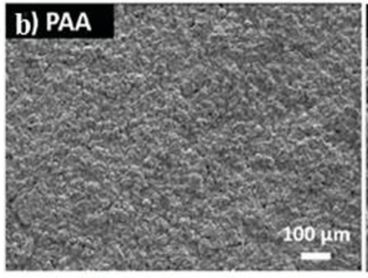

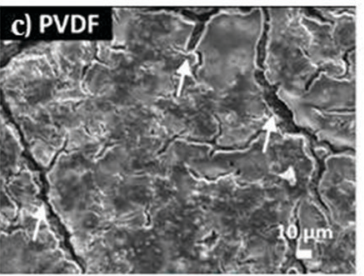

$\mathrm{xNa}_{2} \mathrm{~S}$

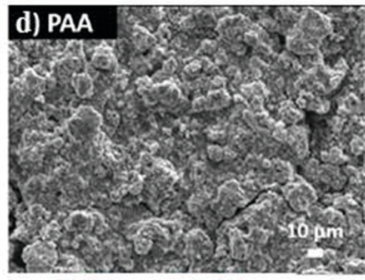

$\mathrm{Na}_{2} \mathrm{~S} \quad \mathrm{xNa}_{2} \mathrm{~S}$

$\mathrm{S}_{\mathrm{x}}$<smiles></smiles>

$\frac{\text { Sodiation }}{\text { Desodiation }}$

$\begin{array}{lllllll} & \mathrm{Na}^{+} & \mathrm{Na}^{+} & \mathrm{Na}^{+} & \mathrm{Na}^{+} & \mathrm{Na}^{+} & \mathrm{Na}^{+}\end{array}$

is is is 'sं is is<smiles>Sc1ccnc2nc3nc4nc5nccc(S)c5c(S)c4c(S)c3c(S)c12</smiles>

f)

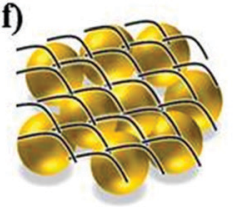

Sulfur
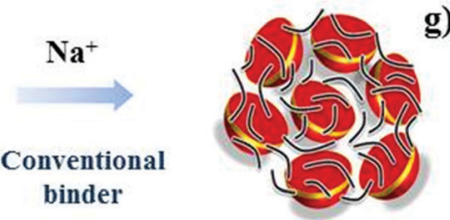

Sodiated Sulfur g)

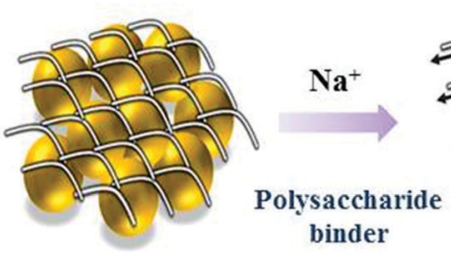

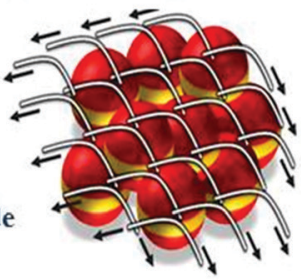

Fig. 3 SEM images of ( $a$ and $c)$ PVDF cathode and ( $b$ and d) PAA cathode at different magnifications. (e) Schematic illustration of the sulfur bonding modes in S-PAN with the corresponding sodiation/de-sodiation reaction. Reproduced with permission. ${ }^{54}$ Copyright 2020 , The Royal Society of Chemistry. ( $f$ and g) Schematic of the proposed role of the conventional and polysaccharide binder to counteract the volume expansion of sulfur during sodium-ion insertion. Reproduced with permission. ${ }^{61}$ Copyright 2019, the American Chemical Society. 


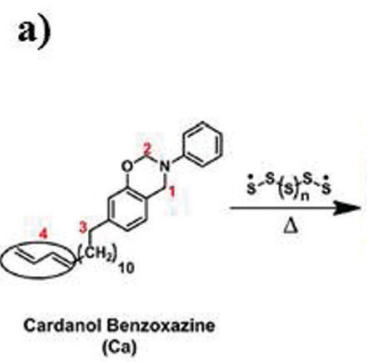

b)

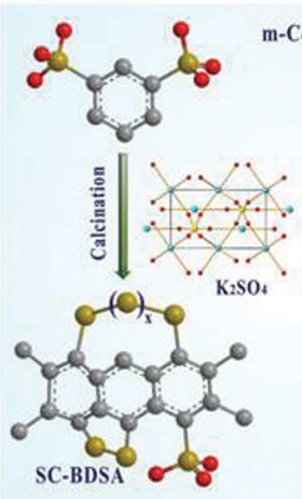

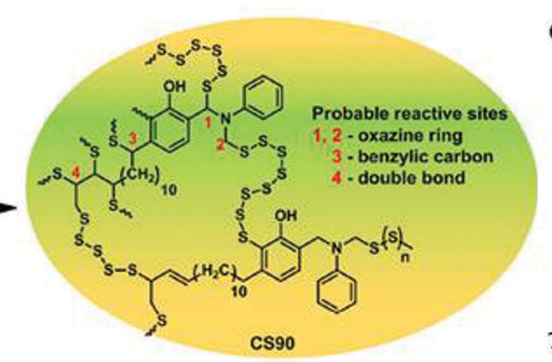

d)

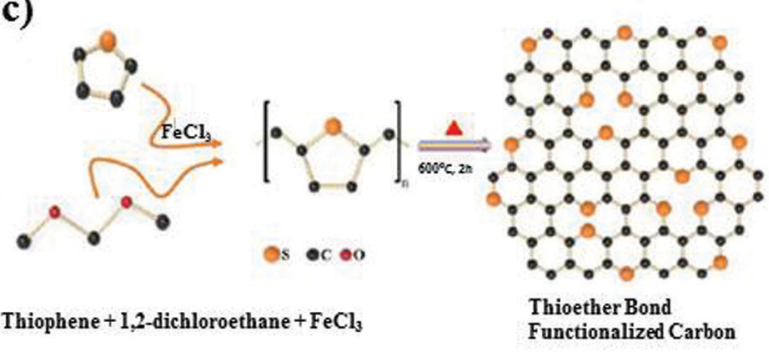

d)

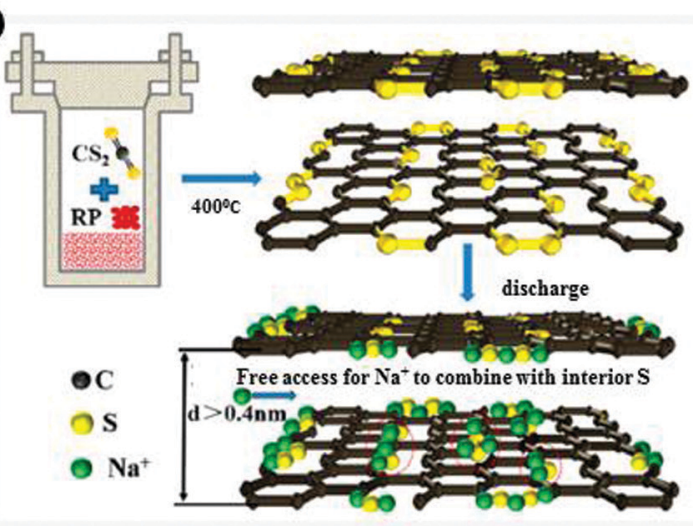

Fig. 4 (a) Chemical structure of copolymer by reaction of Ca monomer with sulfur. Reproduced with permission. ${ }^{30}$ Copyright 2017 , the American Chemical Society. (b) Schematic representation of the synthetic processes of C-BSA, C-BDSA, and SC-BDSA. Reproduced with permission. ${ }^{62}$ Copyright 2019, John Wiley and Sons. (c) Schematic illustration of the synthesis of SC. Reproduced with permission. ${ }^{63}$ Copyright 2019 , The Royal Society of Chemistry. (d) Synthetic route of a covalent sulfur-carbon composite via the solvothermal strategy. Reproduced with permission. ${ }^{64}$ Copyright 2020 , the American Chemical Society.

the structural integrity of the sulfur cathode during the sodium insertion and extraction process, as shown in Fig. 3g. In addition, the hybrid binder of sodium alginate-polyaniline could serve as a conductive matrix to facilitate the movement of ions and electrons and ensured a sulfur loading of about $2.05 \mathrm{mg} \mathrm{cm}^{-2}$.

Another broad approach of covalent fixing can reinforce the strong chemical binding interactions between the sulfur chains and the host molecules. Consequently, Arnab et al. ${ }^{30}$ reported a sulfur-embedded polymer matrix as the host for the cathode material for RT-Na/S batteries with a high sulfur loading of about $90 \mathrm{wt} \%$. The sulfur co-polymer was obtained via a thermal ring-opening polymerization strategy using cardonol-based benzoxazine as the co-monomer (CS-90) (see Fig. 4a), which was then incorporated with reduced graphene oxide (CS-90/rGO). Besides the high reactivity of the co-monomer, the presence of multiple active sites prompted the co-monomer to anchor the polysulfane chains, resulting in an average S-loading of about $2.14 \mathrm{mg} \mathrm{cm}^{-2}$. The high
Similarly, Wu and co-workers proposed a covalently bonded sulfurcarbon composite with benzenedisulfonic acid (SC-BDSA) with $-\mathrm{SO}_{3} \mathrm{H}$ and $\mathrm{SO}_{4}{ }^{-}$as the sulfur source in an RT-Na/S battery system, which ensured an active mass loading of $\sim 3 \mathrm{mg} \mathrm{cm}^{-2}$. ${ }^{62}$ Fig. $4 \mathrm{~b}$ schematically illustrates (1) a short-chain sulfur-carbon composite with a sulfur content of $8.53 \mathrm{wt} \%$, (2) replacing benzenesulfonic acid with di-substituted benzenedisulfonic acid (BDSA) with an increased sulfur content of $18.33 \mathrm{wt} \%$ and (3) replacing the salt template with potassium sulfate, resulting in a high S-content of $40.07 \mathrm{wt} \%$. Due to the $\mathrm{O}-\mathrm{S} / \mathrm{C}-\mathrm{S}$ bridge bonds present in the sulfur species, high conductivity can be maintained to provide excellent interfacial contact among the particles in SC-BDSA. Consequently, the $\mathrm{RS}_{2} \mathrm{O}_{2}^{-}$units formed on the surface of the complex matrix can act as an internal mediator to strongly bind the long-chain sodium polysulfides in the electrolyte. This results in catenating polythionates, which trigger their conversion to short-chain sodium polysulfides, as depicted in the following reaction.

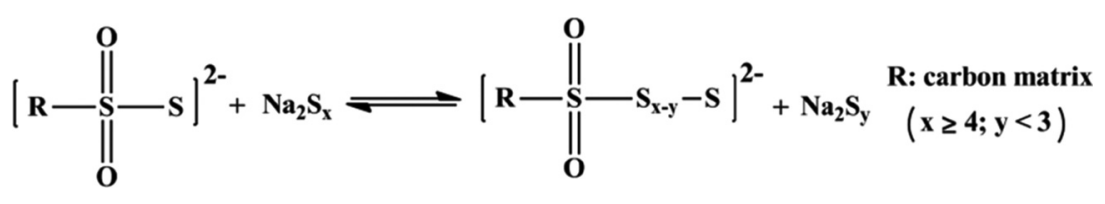

binding effect of the covalently bonded active sulfur with the organic moiety units alleviated the dissolution effect of the sulfur species during cycling. However, the cathode delivered a capacity of $285 \mathrm{~mA} \mathrm{~h} \mathrm{~g}^{-1}$ after 100 cycles at a current density of $0.6 \mathrm{C}$.
The cell exhibited high cyclic stability of 1000 cycles with a minimal decay rate of $0.035 \%$ per cycle with a reversible capacity of $452 \mathrm{~mA} \mathrm{~h} \mathrm{~g}^{-1}$ at $2500 \mathrm{~mA} \mathrm{~g}^{-1}$ and an initial discharge capacity of $696 \mathrm{~mA} \mathrm{~h} \mathrm{~g}^{-1}$. 
Considering the covalent binding effect with sulfur, another group demonstrated the idea of confinement to boost the binding of sulfur with the matrix. Sulfur atoms were confined to a carbon matrix, which was named "thioether bond-functionalized carbon (SC)". ${ }^{63}$ This can be an effective approach to mitigate the dissolution effect of soluble polysulfides. They investigated if the development of sulfur atoms bonded to carbon species can protect the system from reduced sulfur species of long chain-polysulfides owing to the generation of soluble sulfur species $\left(\mathrm{S}^{2-}\right.$ and $\left.\mathrm{S}_{2}{ }^{2-}\right)$ in the routine carbonate electrolyte. SC, containing a thioether bond, can be untied through voltage scissors in the voltage range of $0.01-0.5 \mathrm{~V} v s . \mathrm{Na} / \mathrm{Na}^{+}$and the cell can deliver a large reversible capacity for sodium storage. The insoluble reduced sodium species were then incorporated in the carbon defects induced by the cleaved sulfur (see Fig. 4c), overcoming the detrimental transformation to long-chain polysulfides. However, despite their effort to suppress the shuttle effect, the active material loading obtained was very low at $0.9-1.1 \mathrm{mg} \mathrm{cm}^{-2}$. Recently, Li et al. ${ }^{64}$ studied the in situ preparation of covalent configured carbon sulfur through the wet-chemical solvothermal strategy using carbon disulfide as the precursor in the presence of red phosphorus. S-C bonds were formed with the uniform distribution of sulfur on the periphery and interior of the carbon skeleton, as depicted in Fig. 4d. The ease of access of sodium ions between the carbon interlayer could activate the sulfur species electrochemically under $0.5 \mathrm{~V}$. They claimed that the enlarged interlayer spacing of $\sim 0.4 \mathrm{~nm}$ allowed the free transportation of sodium ions into the matrix, which reacted with sulfur, allowing it to behave as a capacity donor in the subsequent cycles. The covalent cathode composite maintained a high reversible capacity of $811.4 \mathrm{~mA} \mathrm{~h} \mathrm{~g}^{-1}$ after 950 ultra-long cycles at 1.6C. Additionally, the covalent-S-C electrode delivered a remarkable capacity of $700 \mathrm{~mA} \mathrm{~h} \mathrm{~g}^{-1}$ at 8.1C.

2.1.2 Dopants. Besides the exceptional effect of chemical binding on the battery performance, most of the binders are electrochemically inactive and add to the dead weight of the cell and increase the thickness of the materials, and hence the charge-transfer resistance. Therefore, to tune the interaction between sulfur particles and the matrix, other strategies, such as elemental doping of the matrix, have been examined in recently and identified to be highly effective. Due to the multifunctional aspects of elemental doping, i.e., enhanced sulfur loading, improved conversion kinetics and good electronic conductivity of the matrix, various elemental dopants, such as $\mathrm{N}, \mathrm{B}$, and $\mathrm{P}$ have been examined. ${ }^{65-69}$

Recently, Zhang et al. $^{70}$ developed an elemental cobalt (i.e., atomic cobalt)-doped hollow carbon nanosphere matrix for the sulfur cathode, and reported an improved sulfur loading of about $5 \mathrm{mg} \mathrm{cm}^{-2}$. Due to the strong polar interaction between the Co and $\mathrm{S}$ atoms, the matrix could accommodate a high loading of sulfur with improved kinetics in the conversion reactions. Theoretical calculations were performed to understand the kinetically fast reaction of $\mathrm{Na}_{2} \mathrm{~S}$ with the Co-doped matrix, as shown in Fig. 5a and b. The strong binding with the doped matrix allows a complete sodiation reaction, which effectively alleviates the shuttle effect and improves the cycling stability.
The matrix doped with Co-atoms allows the facile adsorption of sodium polysulfides due to the relatively low or negative energy barrier for the adsorption reaction, as shown in Fig. 5c. Thus, this enabled stability for over 600 cycles at a current density of $100 \mathrm{~mA} \mathrm{~g}^{-1}$. The matrix without Co dopant could deliver an

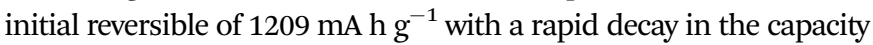
of $271 \mathrm{~mA} \mathrm{~h} \mathrm{~g}^{-1}$ after 600 cycles. Significantly, the addition of cobalt clusters within the matrix enhanced the utilization of sulfur, where the sodium polysulfides confined within the shell of carbon could be catalytically reduced to $\mathrm{Na}_{2} \mathrm{~S}$. This attenuated the dissolution of polysulfides based on the polar-polar interactions, as illustrated in Fig. $5 \mathrm{~d}$ and e.

Zheng et al. studied "a highly feasible nano-copper-assisted immobilizing sulfur in high-surface-area mesoporous carbon (HSMC)" prepared via the multiple wetness impregnation and synchro-dry method with a S-content of $50 \mathrm{wt} \% .{ }^{73}$ In addition to the physical encapsulation of sulfur in the mesoporous carbon, sulfur was also chemically stabilized with the copper nanoparticles, resulting in enhanced conductivity in the composite cathode. The HSMC- $\mathrm{Cu}-\mathrm{S}$ cathode delivered a high discharge capacity of about $610 \mathrm{~mA} \mathrm{~h} \mathrm{~g}{ }^{-1}$ at $0.03 \mathrm{C}$ after 110 cycles with a high Coulombic efficiency of about $100 \%$. Despite the high initial discharge capacity of $\sim 1000 \mathrm{~mA} \mathrm{~h} \mathrm{~g}{ }^{-1}$ and improved kinetics offered by the inclusion of the copper cluster in the matrix, the feasibility of the system was hindered due to its low sulfur loading ( $\sim 1 \mathrm{mg} \mathrm{cm}^{-2}$ with 50 wt $\%$ S-content). Similarly, Zhu et al. ${ }^{74}$ modified the carbon matrix with 0.14 at\% iron atoms and nitrogen to develop a hybrid sulfur cathode. The nitrogen-doped carbon nanospheres can expedite the transport of ions and electrons, whereas the iron atoms serve as catalytic sites for stronger chemical interaction and conversion for the discharge products of sulfur. The hybrid cathode could deliver a reversible capacity of $359 \mathrm{~mA} \mathrm{~h} \mathrm{~g}^{-1}$ and $180 \mathrm{~mA} \mathrm{~h} \mathrm{~g}^{-1}$ at a current density of $0.1 \mathrm{~A} \mathrm{~g}^{-1}$ and $1 \mathrm{~A} \mathrm{~g}^{-1}$, respectively, with a high coulombic efficiency of about $100 \%$ after 200 cycles. Recently, Wang et al. introduced "an effective sulfiphilic matrix," i.e., gold nanodot-decorated hierarchical N-doped carbon microspheres $(\mathrm{CN} / \mathrm{Au} / \mathrm{S}) .{ }^{71}$ Due to the high affinity of $\mathrm{CN} / \mathrm{Au}$ towards sulfur atoms, a high sulfur content of about $56.5 \mathrm{wt} \%$ could be achieved. The matrix doped with gold nanodots (i.e., $\mathrm{CN} / \mathrm{Au} / \mathrm{S}$ ) exhibited a higher binding energy for sulfur atoms compared to the matrix without dopant, indicating the strong interaction between the sulfur particles and gold nanodots, consequently trapping the sodium polysulfides during the cycling process. Apparently, the high binding energies of the elemental sulfur and sodium polysulfides upon the addition of gold clusters demonstrate their effectiveness in achieving a higher sulfur loading. The presence of gold nanodots enhanced the adsorption between the matrix and polysulfides $\left(\mathrm{Na}_{2} \mathrm{~S}_{n} ; 4 \leq\right.$ $n \leq 1$ ), which helped alleviate the shuttle effect to a great extent. The as-modified matrix in the sulfur cathode exhibited longterm cycling stability, retaining a capacity of about $430 \mathrm{~mA} \mathrm{~h} \mathrm{~g}{ }^{-1}$ after 1000 cycles, and a reversible capacity of about $369 \mathrm{~mA} \mathrm{~h} \mathrm{~g}^{-1}$ after 2000 cycles at a current density of $2 \mathrm{~A} \mathrm{~g}^{-1}$ and $10 \mathrm{~A} \mathrm{~g}^{-1}$, respectively. This is attributed to the fact that sulfur and its discharged species show higher absorption energies over $\mathrm{CN} / \mathrm{Au}$ compared to the matrix without gold nanodots, as shown in Fig. $5 \mathrm{f}$. 
a)

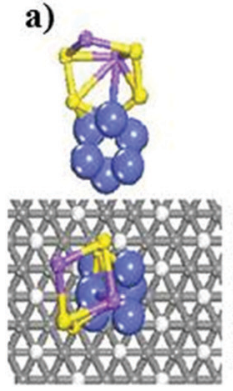

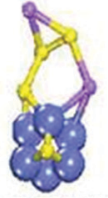

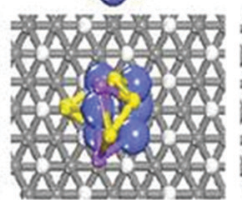

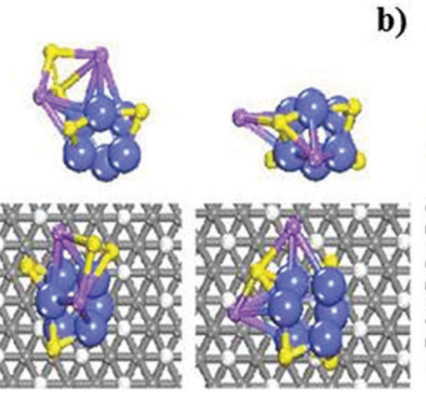

b)

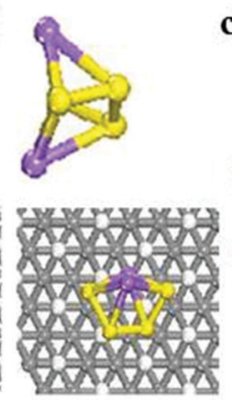

c)

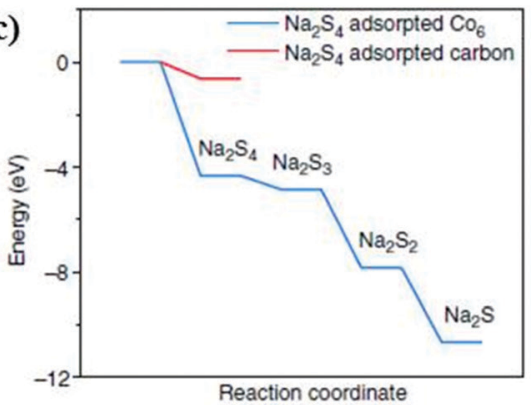

f)

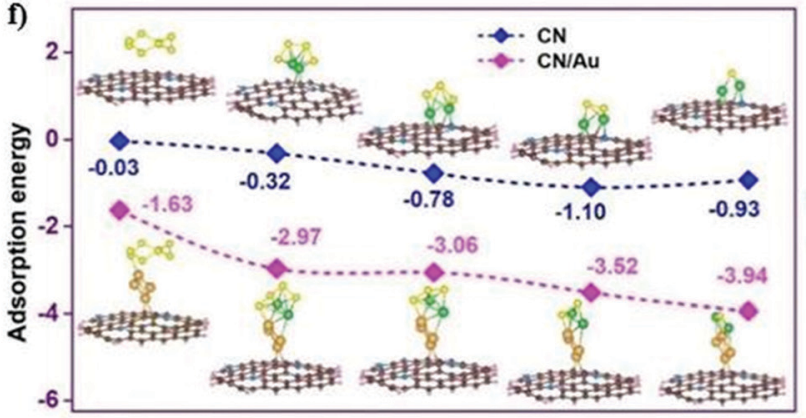

g)

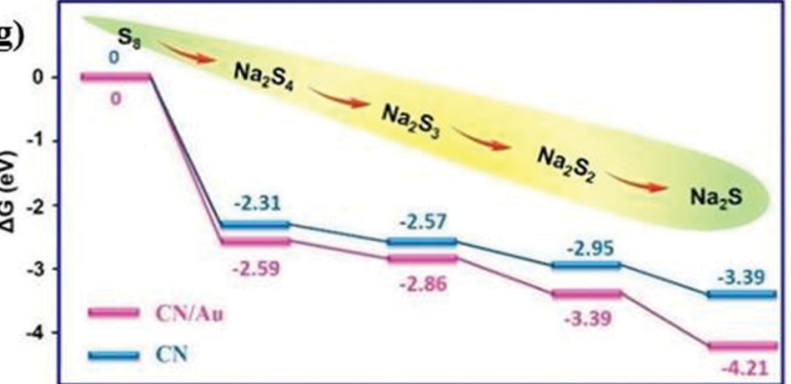

d)

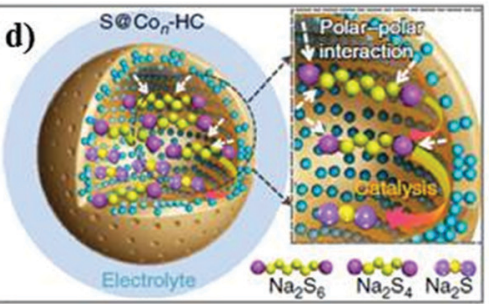

h) S@pPAN/ Slow Kinetics

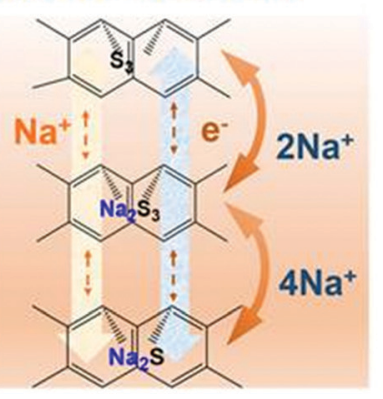

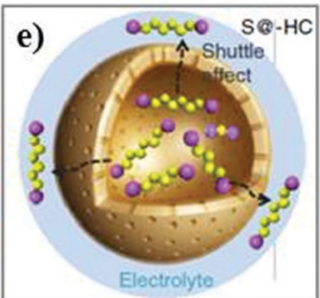

$\mathrm{Te}_{0.04} \mathrm{~S}_{0.96} @$ pPAN/ Fast Kinetics

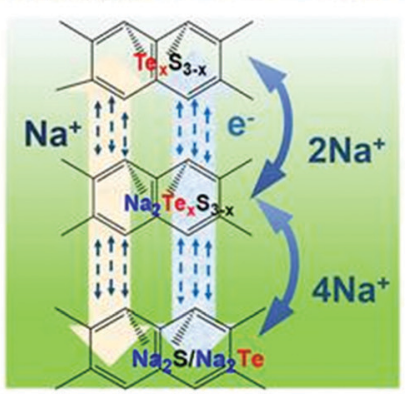

Fig. 5 Density functional theory results and electrode reaction mechanism. (a) Optimized structures of $\mathrm{Na}_{2} \mathrm{~S}_{4}$ cluster on carbon-supported $\mathrm{Co}_{6}$ cluster

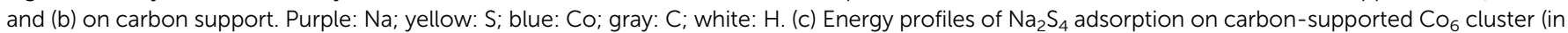
blue) and carbon support (in red). (d) Schematic illustration of the electrode reaction mechanism of atomic cobalt-decorated hollow carbon-sulfur host (S@Con-HC) and (e) hollow carbon hosting sulfur (S@HC), respectively. Reproduced with permission. ${ }^{70}$ Copyright 2018, Springer Nature. (f) Adsorption energies and (g) Gibbs free energies of NaPSs bound on the nitrogen-doped carbon surface and Au-decorated nitrogen-doped carbon. Reproduced with permission. ${ }^{71}$ Copyright 2020, The Royal Society of Chemistry. (h) Reaction pathway for $\mathrm{Te}_{0.04} \mathrm{~S}_{0.96} @ \mathrm{apPAN}$ and S@pPAN composites and hollow carbon hosting sulfur (S(HC), respectively. Reproduced with permission. ${ }^{72}$ Copyright 2019, the American Chemical Society.

In addition, the lower Gibbs free energy change for the gold doped matrix suggests the spontaneity of the reaction, resulting in enhanced adsorption capability, which efficiently mitigates the polysulfides shuttling, as shown in Fig. $5 \mathrm{~g}$.

Intrigued by the effect of elemental doping, Li et al. ${ }^{72}$ altered the SPAN matrix with tellurium atoms to form a sulfur cathode for RT-Na/S. The reaction kinetics were greatly improved with a high sulfur content of about $47.77 \mathrm{wt} \%$ of the active material. The tellurium-doped SPAN enhanced the reversible kinetics of the system (see Fig. 5h) with improved reversibility. Besides the fast reaction kinetics and the high electrochemical performance of $\mathrm{Te}_{0.04} \mathrm{~S}_{0.96} @ p P A N$, a high sodium ion diffusion coefficient and a higher electronic conductivity of at least 1.6 times that of pPAN@S could be achieved with $\mathrm{Te}_{0.04} \mathrm{~S}_{0.96} @ \mathrm{pPAN}$. The cycle-life of over 600 cycles was attained with the $\mathrm{Te}_{0.04} \mathrm{~S}_{0.96} @$ pPAN cathode, retaining a discharge capacity of about $970 \mathrm{~mA} \mathrm{~h} \mathrm{~g}{ }^{-1}$ at $0.5 \mathrm{~A} \mathrm{~g}^{-1}$ with a decay of about $0.015 \%$ per cycle. Due to the unique attributes of the $\mathrm{Te}_{0.04} \mathrm{~S}_{0.96} @ \mathrm{pPAN}$ cathode (i.e., high electronic and ionic conductivity, and fast conversion kinetics), it demonstrated an excellent rate capability at various current densities $\left(0.1 \mathrm{~A} \mathrm{~g}^{-1}\right.$ to $\left.6 \mathrm{~A} \mathrm{~g}^{-1}\right)$. It is apparent from the literature that the chemical modification of the matrix of the sulfur cathode significantly improves the battery performance, and it is anticipated that the role of chemical binding will create more opportunities to further improve the sulfur loading without compromising the fast reaction kinetics.

\subsection{Physical aspects}

The poor ionic conductivity of sulfur and relatively large size of $\mathrm{Na}^{+}$ions result in extreme electronic and mechanical stress in the matrix. ${ }^{75,76}$ Therefore, it is desirable for the matrix to have a provision for altering the electronic conductivity to improve the electron transfer between the electrode/electrolyte interface without experiencing volume changes upon charge-discharge in the sulfur cathode. Due to limited availability of electronic and ionic sites in the conventional matrix, the RT-Na/S battery 
loses its capacity very fast. ${ }^{77}$ Thus, to promote the electrochemical stability, different strategies have been developed to alter the physical structure of the matrix (i.e., 1D, 2D and 3D structures) to concomitantly restrict polysulfides at the cathode and virtually eliminate their dissolution in the electrolyte.

2.2.1 One-dimensional matrix materials (1D matrix). A significant achievement has been made in altering the structure of the matrix materials to overcome the weak-interaction between sulfur particles and the matrix materials. ${ }^{78}$ One-dimensional nanofiber matrices, such as polyacrylonitrile (PAN), have previously been used due to the infusion of sulfur particles and widely utilized as a cathode material due to their high electronic conductivity for both lithium-sulfur and sodiumsulfur batteries. ${ }^{54,79-82}$ Hwang and co-workers ${ }^{83}$ reported a polyacrylonitrile-derived carbon/sulfur composite matrix to support the cathode material for the RT-Na/S battery. The sulfur content obtained was about $31.42 \mathrm{wt} \%$. The one-dimensional (1D) matrix, i.e., PAN nanofibres with a uniform diameter of $\sim 160 \mathrm{~nm}$, was prepared via an electrospinning method. The sulfur was infused under heat treatment with sulfur powder, which resulted in a 1D matrix structure in the PAN@C/S composite cathode. The 1D matrix, which was composed of " $\pi$-conjugated ring structures covalently bonded to sulfur species," could deliver an excellent electrochemical performance due to its (1) high electronic conductivity to facilitate electron transfer, (2) polar groups to alleviate the dissolution of sodium polysulfides, and (3) facilitating the kinetics of the conversion reactions. Furthermore, by employing the 1D structure of cPANS with a controlled morphology, the cathode could deliver cycling stability for over 500 cycles at $0.1 \mathrm{C}$, as shown in Fig. $6 \mathrm{a}$ and b. The $1 \mathrm{D}$ matrix could enable a total sulfur loading of about $1.0-1.2 \mathrm{mg} \mathrm{cm} \mathrm{cm}^{-2}$. However, despite the appreciable electronic conductivity and excellent stability, a desirable sulfur loading $\left(>3 \mathrm{mg} \mathrm{cm} \mathrm{cm}^{-2}\right.$ ) could not be achieved. Li et al. analyzed a 1D framework of selenium disulfide with pyrolysed PAN (pPAN). ${ }^{84}$ The 1D matrix maintained a large aspect ratio with the added advantages of a high surface area and directional propagation of ions. $\mathrm{pPAN} / \mathrm{SeS}_{2}$ as a cathode for an RT-Na/S battery at a current density of $1 \mathrm{Ag}^{-1}$ could deliver an initial discharge capacity of about $1043 \mathrm{~mA} \mathrm{~h}^{-1}$ and a stable specific capacity of about $800 \mathrm{~mA} \mathrm{~h} \mathrm{~g}{ }^{-1}$ after 400 cycles. With an increase in the current density, $\mathrm{pPAN} / \mathrm{SeS}_{2}$ exhibited a capacity of $\sim 302 \mathrm{~mA} \mathrm{~h} \mathrm{~g}^{-1}$ even at $5 \mathrm{~A} \mathrm{~g}^{-1}$ and the sulfur loading that could be achieved was about $2 \mathrm{mg} \mathrm{cm}^{-2}$ with a mass content of nearly $63 \mathrm{wt} \%$. The high sulfur loading could be credited to the multi-functionality of the $1 \mathrm{D}$ matrix-based sulfur cathode, including its high surface area and amorphous structure. pPAN/SeS $S_{2}$ exhibited improved chemical reaction kinetics, high sulfur utilization and a robust matrix structure, enabling it to withstand the constant volume changes during cycling.

Generally, metal oxides are non-conductive with abundant active polar sites due to their oxygen ions. A judiciously designed metal oxide with polar sites may lead to a higher loading of sulfur, and simultaneously exhibit a high volumetric energy density with limited diffusion of polysulfides. ${ }^{87,88} \mathrm{Ma}$ et al. implemented a new strategy for mitigating the shuttle effect by employing an amorphous structured transition metal oxide on a ferroelectric-encapsulated composite cathode to achieve high ionic transport across the electrode materials. ${ }^{85}$ The composite cathode was fabricated through a carbonization process and melt diffusion strategy with the active mass loading of about $1.2-1.4 \mathrm{mg} \mathrm{cm}^{-2}$, as shown in Fig. 6c and d. The electrochemical results for $\mathrm{CSB}_{3} \mathrm{TiO}_{2}$ were compared with that of pure $\mathrm{C} / \mathrm{S}$ and $\mathrm{C} / \mathrm{S} / \mathrm{BaTiO}_{3}$, and it was found that the hybrid cathode CSB@TiO ${ }_{2}$ exhibited a superior performance. This can be attributed to the synergistic morphology of the atomic layer deposited layer on the surface of $\mathrm{C} / \mathrm{S} / \mathrm{BaTiO}_{3}$. The $\mathrm{CSB} @ \mathrm{TiO}_{2}$, $\mathrm{C} / \mathrm{S} / \mathrm{BaTiO}_{3}$, and $\mathrm{C} / \mathrm{S}$ electrodes displayed a specific capacity of $1020 \mathrm{~mA} \mathrm{~h} \mathrm{~g}^{-1}, 1101 \mathrm{~mA} \mathrm{~h} \mathrm{~g}^{-1}$ and $1120 \mathrm{~mA} \mathrm{~h} \mathrm{~g}^{-1}$, respectively, where a high reversible capacity of $611 \mathrm{~mA} \mathrm{~h} \mathrm{~g}{ }^{-1}$ could be retained for the $\mathrm{CSB}_{2} \mathrm{TiO}_{2}$ cathode after 400 cycles. The cycling performance was evaluated at an even higher sulfur loading of about $3.3-3.5 \mathrm{mg} \mathrm{cm}^{-2}$, and the initial specific capacity at $0.5 \mathrm{~A} \mathrm{~g}^{-1}$ was $1055 \mathrm{~mA} \mathrm{~h} \mathrm{~g}^{-1}$ for $\mathrm{C} / \mathrm{S}, 1040 \mathrm{~mA} \mathrm{~h} \mathrm{~g}{ }^{-1}$ for

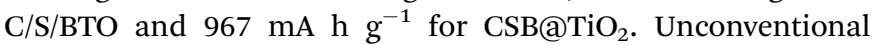
battery systems using cable-type configurations have been recently explored to provide an efficient capacity for battery devices. ${ }^{89}$ Xin et al. reported a composite cathode comprising co-axial cable-like carbon nanotubes with a mean diameter of $0.5 \mathrm{~nm}$ in a sulfur-infused microporous carbon matrix. ${ }^{86} \mathrm{~S} / \mathrm{CNT} @$ MPC exhibited a sulfur content of about $40 \%$ with an overall active material loading of $1 \mathrm{mg} \mathrm{cm}{ }^{-2}$. The cable-like structure provides a facile pathway for the movement of ions and electrons (Fig. 6e) without deteriorating the attributes of the 1D microporous matrix. The cathode with small sulfur molecules could deliver a high capacity of $1610 \mathrm{~mA} \mathrm{~h} \mathrm{~g}^{-1}$ in addition to displaying a high rate performance of $815 \mathrm{~mA} \mathrm{~h} \mathrm{~g}^{-1}$ even at a high C-rate of $2 \mathrm{C}$. The high performance of S/CNT@MPC was attributed to the complete reduction of sodium polysulfides. An ultra-microporous carbon with a pore diameter of less than $0.7 \mathrm{~nm}$ can be more effective in providing better absorption sites for entrapping sodium polysulfides. ${ }^{90}$ The matrix was fabricated through an activationfree approach, and the elemental sulfur particles were infused under thermal treatment. Owing to the ultra-microporosity in the $3 \mathrm{D}$ matrix, the cell could deliver a reversible discharge capacity of $392 \mathrm{~mA} \mathrm{~h} \mathrm{~g}^{-1}$ after 200 cycles with a high Coulombic efficiency close to $100 \%$ at $1 \mathrm{C}$.

2.2.2 Two-dimensional matrix materials (2D matrix). Owing to the high surface area, good electronic conductivity, and porous structure, carbon-based composites have widely been used as a 2D matrix for sulfur cathodes in Li-S battery systems. ${ }^{91-96} \mathrm{Kim}$ and co-workers reported a 2D matrix-based carbon/sulfur composite cathode, which was synthesized using an activated carbon precursor with a high pore volume $\left(0.7932 \mathrm{~cm}^{3} \mathrm{~g}^{-1}\right)$ and surface area $\left(1696 \mathrm{~m}^{2} \mathrm{~g}^{-1}\right)$, delivering a high discharge capacity of about $855 \mathrm{~mA} \mathrm{~h} \mathrm{~g}{ }^{-1} \cdot{ }^{97}$ The conventional cathode comprising a mixture of sulfur particles, PVDF and super-P conductive fillers exhibited a homogeneous well-distributed porous structure with a clean surface. However, after a few tens of cycles, nanometre-sized overgrown particles on the surface in direct contact with the electrolyte were observed on its surface. The particles were determined to be deposits of sodium polysulfides $\left(\mathrm{Na}_{2} \mathrm{~S}_{n} ; 1 \leq\right.$ $n \leq 3)$. Conversely, a 2D matrix with composite sulfur cathode 
a)

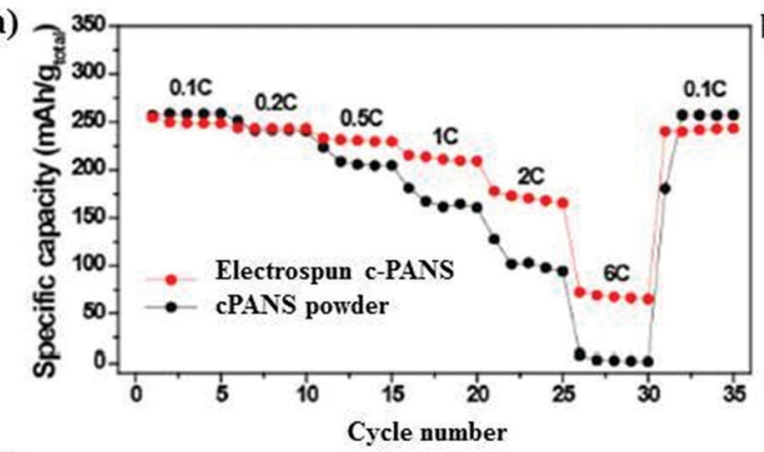

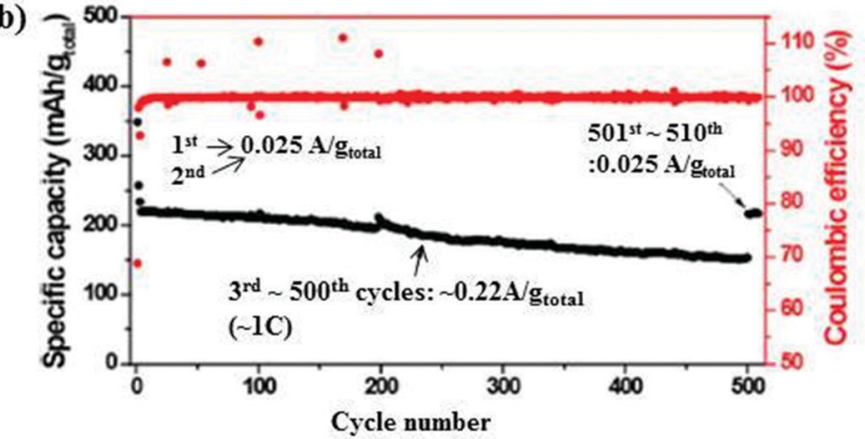

c)
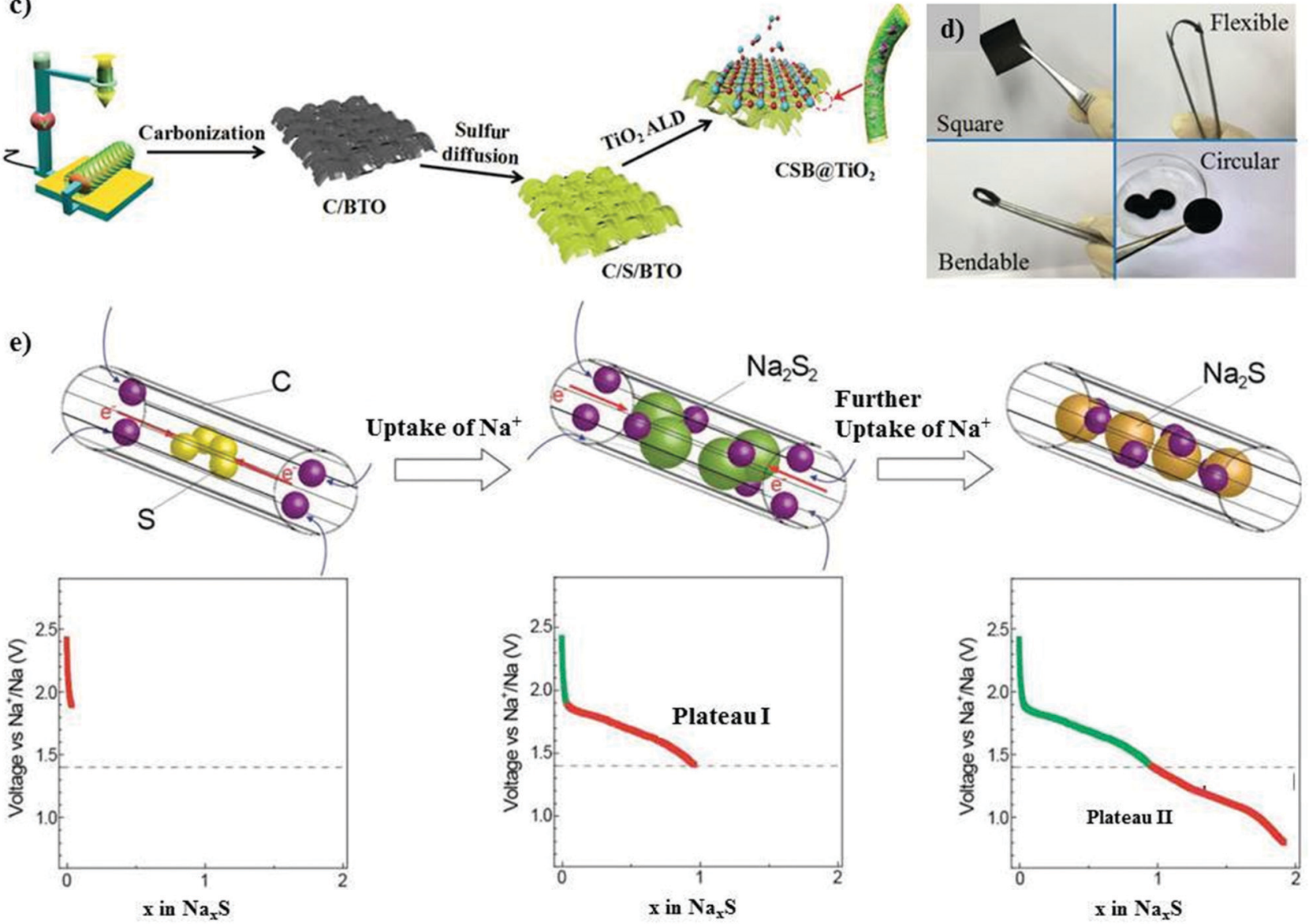

Fig. 6 (a) Rate performances of the electrospun c-PANS NFs and C-PANS powder measured at various C-rates. The C-rates were the same for both charge and discharge in each cycle. (b) Capacity retention and Coulombic efficiencies of C-PANS NFs. The sample was measured at a low C-rate of $0.1 \mathrm{C}$ (0.025 A g $\mathrm{A}^{-1}$ total) in the first two and final ten cycles, but at a higher $\mathrm{C}$-rate of $1 \mathrm{C}\left(0.22 \mathrm{~A} \mathrm{~g}^{-1}\right.$ total) in the cycle range of $3-500$. Reproduced with permission. ${ }^{83}$ Copyright 2013, the American Chemical Society. (c) Schematic illustration of the preparation of the CSB@TiO $\mathrm{Clectrode}_{2}$ (d) Photograph of the CSB@TiO ${ }_{2}$ free-standing electrode. Reproduced with permission. ${ }^{85}$ Copyright 2018, John Wiley and Sons. (e) Electrochemical reaction between S and $\mathrm{Na}^{+}$ions during the discharge process in S/(CNT@MPC). Reproduced with permission. ${ }^{86}$ Copyright 2013, John Wiley and Sons.

could maintain a reversible capacity of about $521 \mathrm{~mA} \mathrm{~h} \mathrm{~g}^{-1}$ with a Coulombic efficiency of $\sim 100 \%$. However, although it could maintain a good specific capacity, the capacity fade per cycle and decay in the Coulombic efficiency were very high, which could likely be due to the partial attachment of the sulfur particles to the solid electrolyte layer. The capacity fade may also be contributed by the resistive nature of the SEI. In addition, the decay can be ascribed to the increased thickness of the coated material on the metal foil, which impedes electrolyte infiltration inside the material, resulting in slower kinetics of the discharge reactions. Hu and co-workers used elemental sulfur particles to coat nanosized composites with a suitable promotor to accelerate the kinetics of the sulfur reactions. ${ }^{98}$ Accordingly, pre-milled commercial sulfur $(10 \mu \mathrm{m}$ average size) with processed nanocarbon as the promotor was utilized as the composite cathode material for RT-Na/S. The TGA results depicted a high loading of sulfur, i.e., about $61.1 \mathrm{wt} \%$ and a S-loading of $0.8-2.0 \mathrm{mg} \mathrm{cm}^{-2}$ could be maintained. 
The increased performance using processed carbon compared to the pristine carbon can be attributed to the increased number of vacancy defects for the processed nanocarbon with an increased pore volume of $<0.7 \mathrm{~nm}$. Based on the Raman shift (1516-1541 $\mathrm{cm}^{-1}$ ) and differential scanning calorimetry curves (shaded region), a greater number of defects was observed in the processed nanocarbon compared to the pristine carbon (Fig. 7a and b). The facile nanocarbon was processed via a high energy ball milling process, resulting in an enhancement in the specific capacity in the sulfur cathode from 400 to $713 \mathrm{~mA} \mathrm{~h} \mathrm{~g}^{-1}$ at a C-rate of $0.2 \mathrm{C}$. The cell delivered a high reversible capacity of $>700 \mathrm{~mA} \mathrm{~h} \mathrm{~g}^{-1}$ with a retention rate of about $98.2 \%$ at $0.2 \mathrm{C}$ after 200 cycles, maintaining a Coulombic efficiency of $\sim 100 \%$ (see Fig. 7c).

Recently, an effective polysulfide anchoring composite was formulated by Sajjad and co-workers, where they studied $2 \mathrm{D}$ polar nitrogenated holey graphene $\left(\mathrm{C}_{2} \mathrm{~N}\right)$ and non-polar polyaniline $\left(\mathrm{C}_{3} \mathrm{~N}\right){ }^{100}$ The bilayer polar $\mathrm{C}_{2} \mathrm{~N}$ was superior to the non-polar $\mathrm{C}_{3} \mathrm{~N}$ in terms of its efficiency as an electrode enhancer for improving the conductivity of the sulfur cathode, thus attenuating the shuttle phenomena. A pure carbonaceous material system is relatively less or non-polar in nature, which impedes its practicality due to the weaker binding in confining the metal polysulfides. ${ }^{101-104}$ Recently, researchers have exploited metal-based composites as a possible matrix for the sulfur cathode owing to their highly polar nature and remarkable theoretical specific capacity values. ${ }^{105-108}$ Attributed to the highly polar sites within the 2D metal-based composite matrix, the additional benefits of strong "sulfiphilic" sites can be exploited. ${ }^{106}$ Consequently, an allotrope of molybdenum sulfide as the cathode has recently been examined with the aim of enhancing the loading of sulfur for the sulfur cathode in the RT-Na/S battery system. Ye et al. reported an amorphous structured $\mathrm{MoS}_{3}$ a "the sulfurequivalent cathode material" for RT-Na/S batteries. ${ }^{99}$ A remarkable loading of about $7.1 \mathrm{mg} \mathrm{cm}{ }^{-2}$ was achieved for the $\mathrm{MoS}_{3} / \mathrm{S}$ composite cathode, which is attributed to its unique atomic arrangement, where the Mo atoms were bridged between the sulfur and di-sulfur ligands. $\mathrm{MoS}_{3}$ as a cathode exhibited good electrochemical cycling stability for over 1000 cycles at $0.45 \mathrm{~A} \mathrm{~g}^{-1}$ with a Coulombic efficiency of $\sim 100 \%$, as shown in Fig. $7 d$. At a current density of $0.5 \mathrm{~A} \mathrm{~g}^{-1}$, the cathode maintained the initial discharge capacity of $\sim 248 \mathrm{~mA} \mathrm{~h} \mathrm{~g}{ }^{-1}$ with $\sim 76 \%$ capacity retention after 200 cycles, as illustrated in Fig. 7e. Operando X-ray absorption spectroscopy (XAS) was performed to observe the S K-edge XANES spectrum in the sulfur composite during the charge-discharge process. Profound changes were observed during the discharging of the sulfur cathode, which could be due to the strong interaction between the sulfur and sodium ions, as shown in Fig. $7 f$.

Kim et al. developed a flexible 2D matrix using a SPAN web/S composite as the cathode material for the RT-Na/S battery. ${ }^{82}$ The flexible web was prepared through a two-step electrospinning method followed by pyrolysis. The sulfur content was estimated to be about $41 \mathrm{wt} \%$. The as-developed cathode exhibited good stability for over 200 cycles without any deterioration, dents, or cracks. The discharge capacity of about $343 \mathrm{~mA} \mathrm{~h} \mathrm{~g}^{-1}, 257 \mathrm{~mA} \mathrm{~h} \mathrm{~g}^{-1}$, and $266 \mathrm{~mA} \mathrm{~h} \mathrm{~g}^{-1}$ could be achieved in the 1st, 2nd, and 200th cycles, respectively. Zhu et al. studied carbonized PAN (cPAN) with sulfur as a sulfur cathode for the $\mathrm{Na} / \mathrm{S}$ battery system. ${ }^{109}$ The sulfur loading was estimated to be about $0.79 \mathrm{mg} \mathrm{cm}^{-2}$.
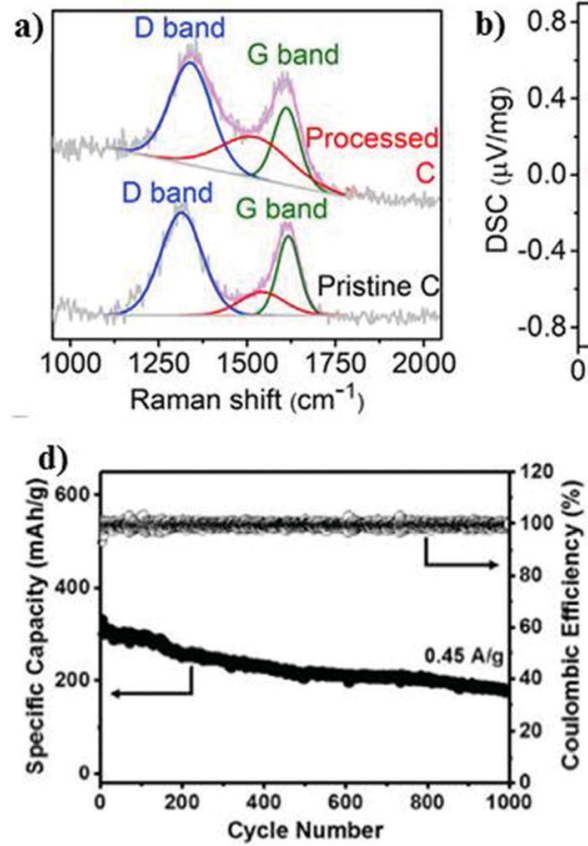

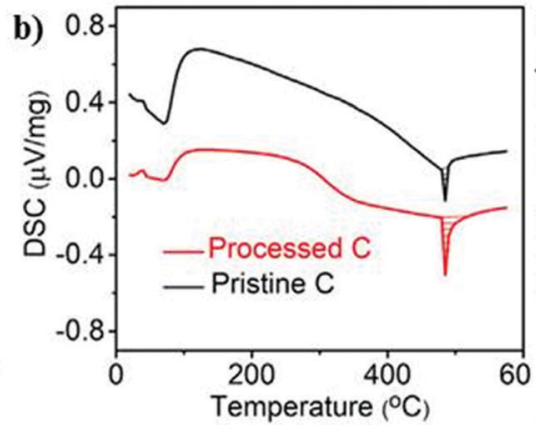

e)

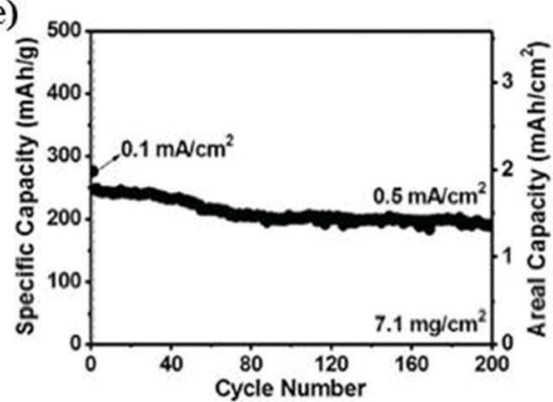

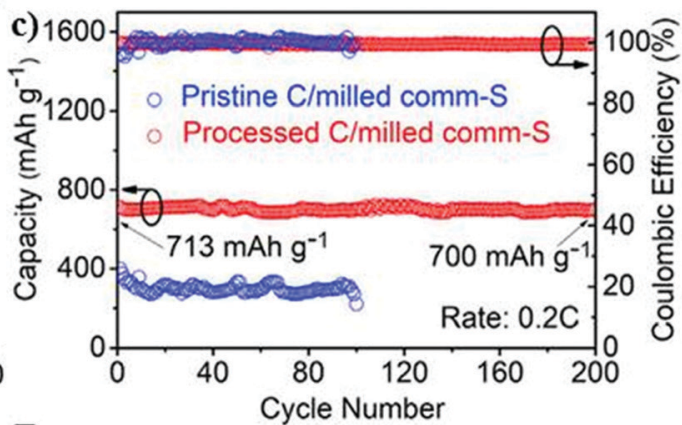

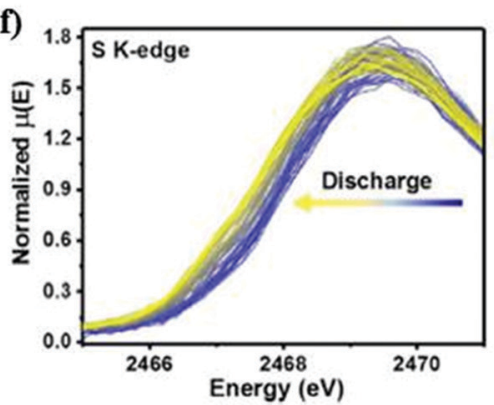

Fig. 7 (a) Raman spectra and (b) DSC curves of pristine and processed C. (c) Cycling performance at 0.2C. Reproduced with permission. ${ }^{98}$ Copyright 2020, Elsevier. (d) Cycling stability and corresponding Coulombic efficiency at $0.45 \mathrm{~A} \mathrm{~g}^{-1}$. (e) Cycling stability of a high-loading electrode (7.1 mg cm $\mathrm{cm}^{-2}$ ) at $0.1 \mathrm{~mA} \mathrm{~cm}{ }^{-2}$ for the first few cycles, and subsequently $0.5 \mathrm{~mA} \mathrm{~cm}{ }^{-2}$. (f) Evolution of $\mathrm{S}$ K-edge XANES spectrum during sodiation. Reproduced with permission. ${ }^{99}$ Copyright 2017, National Academy of Sciences. 
The cell delivered a discharge capacity of about $311 \mathrm{~mA} \mathrm{~h} \mathrm{~g}^{-1}$, while maintaining a high Coulombic efficiency of $\sim 100 \%$ after 100 cycles.

Recently, Ma and co-workers examined a "carbon-wrapped nano-cobalt anchored graphene aerogel."110 The matrix was fabricated through a heat-treatment method with $\mathrm{Co} / \mathrm{rGO}$ and $\mathrm{S}$ in the weight ratio of $6: 4$, as illustrated in Fig. 8a-c. The framework of the graphene aerogel could provide a platform for successfully entrapping the sulfur particles, while the Co nanoparticles accelerated the kinetics of the conversion reactions, as shown in Fig. 8d-g. In addition, the nano-sized cobalt nanoparticles offered active sites for sulfur and its discharge products. The interconnected porous framework of graphene buffered the volume fluctuations during the cycling process. Consequently, the cathode delivered the initial discharge capacity of $572.8 \mathrm{~mA} \mathrm{~h} \mathrm{~g}{ }^{-1}$ at $5 \mathrm{C}$ with a minimal decay rate of $0.01 \%$ per cycle.

2.2.3 Three-dimensional matrix materials (3D matrix). Owing to their high mechanical stability, abundant adsorption sites, high electrical and ionic conductivities, and highly accessible surface area, 3D matrices or infiltrated scaffolds are widely used to support the active materials, thereby attracting increasing attention in RT-Na/S batteries. ${ }^{111-113}$ 3D matrix structures contain sufficient void spaces in their self-woven morphology and high porosity, enabling the matrix to accommodate and support a large amount of active materials. The interconnected morphology results in a high sulfur loading and improved wettability, which significantly improve the specific capacity and reduce the diffusion pathways for both ions and electrons. ${ }^{114-116} 3 \mathrm{D}$ interconnected matrices can be assembled from primary building components, such as $1 \mathrm{D}$ carbon nanotubes and carbon nanofibres, 2D graphene, and other 2D analogues. Lu et al. ${ }^{111}$ examined the performance of 3D interconnected flexible carbon fibre cloth/sulfur (CFC/S) as an electrode material. The CFC/S material with a sulfur loading of about $2 \mathrm{mg} \mathrm{cm}^{-2}$ exhibited the 1st discharge capacity of about $390 \mathrm{~mA} \mathrm{~h} \mathrm{~g}{ }^{-1}$ and retained a reversible capacity of about $120 \mathrm{~mA} \mathrm{~h} \mathrm{~g}^{-1}$ after 300 cycles.
By combining the solution impregnation method and melt diffusion process, the resultant composite of $\mathrm{CFC} / \mathrm{S}$, which consisted of a cellulose interwoven fibrous structure, rendered enough space to support sulfur and its discharge products to achieve an increased sulfur loading of close to $3 \mathrm{mg} \mathrm{cm}^{-2}$. However, with a further increase in the sulfur loading, the sulfur cathode experienced higher polarization, which could be due to the increase in charge transfer resistance.

3D infiltrated electrodes are promising matrix candidates, where sulfur can be infused into the 3D interconnected pores via different techniques, such as melt diffusion and vapor phase infiltration. ${ }^{117,118}$ The 3D infiltrated matrix offers alluring characteristics, which can be useful to improve the transportation kinetics, while increasing the thickness of the electrode materials. ${ }^{119,120}$ Unlike 3D assembled electrodes, microporous carbon with a size of $<2 \mathrm{~nm}$ enhances the conductivity of the sulfur cathode, which can be designed to act as a strainer to successfully confine sulfur polysulfides. ${ }^{121}$ As a proof-of-concept, Carter et al. designed microporous carbon derived from sugar as a 3D matrix to support elemental sulfur. ${ }^{117}$ Sulfur particles were infused through a vapor infiltration chemical processing method, which could provide stable adsorption and successful confinement of the sulfur species, as schematically shown in Fig. 9a. The composite cathode demonstrated a stable performance for over 1500 cycles with the Coulombic efficiency of over $98 \%$. The reversible capacity of about $300 \mathrm{~mA} \mathrm{~h} \mathrm{~g}^{-1}$ could be obtained at $1 \mathrm{C}$, whereas the cell could deliver a discharge capacity of $\sim 700 \mathrm{~mA} \mathrm{~h} \mathrm{~g}{ }^{-1}$ at $0.1 \mathrm{C}$. The successful infiltration and confinement of sulfur in the microspheres alleviated the shuttle effect and maintained the stability of the cathode, but the sulfur content was about 35 wt\%, which is much lower than the practical requirement. Despite the effective immobilization of sulfur offered by microporous carbon, its performance as a 3D matrix to hold sulfur is still impeded by its non-polar nature, uncontrollable porosity, and weak physio-sorption. ${ }^{122}$ Additionally, microporous
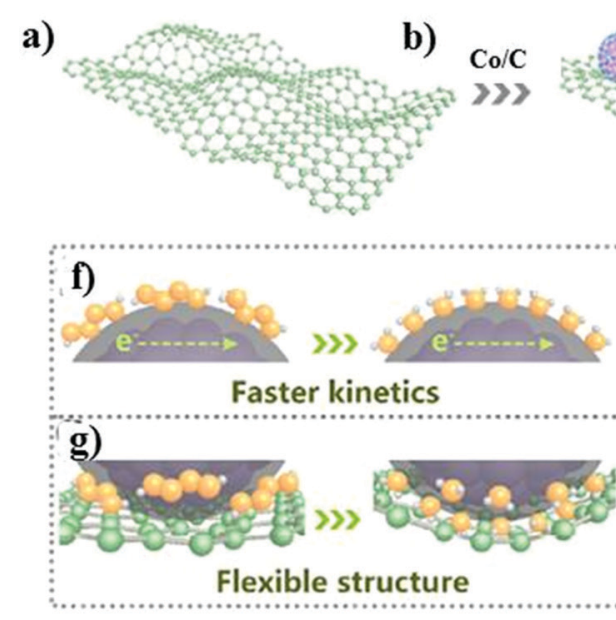

\section{Graphene}

Fig. 8 Schematic illustration of the S@Co/C/rGO electrode design. (a-c) Illustration of the synthesis. (d-g) Advantages of the SaCo/C/rGO composite. Reproduced with permission. ${ }^{110}$ Copyright 2020, Elsevier. 
a)

$\begin{array}{cc}\text { Sucrose } & \text { Amorphous } \\ \left(\mathrm{C}_{12} \mathrm{H}_{22} \mathrm{O}_{11}\right) & \text { Carbon (C) }\end{array}$

\section{Ordered Microporous Carbon Spheres (C)}

\section{Sulfur Infiltrated \\ Spheres (S@C)}
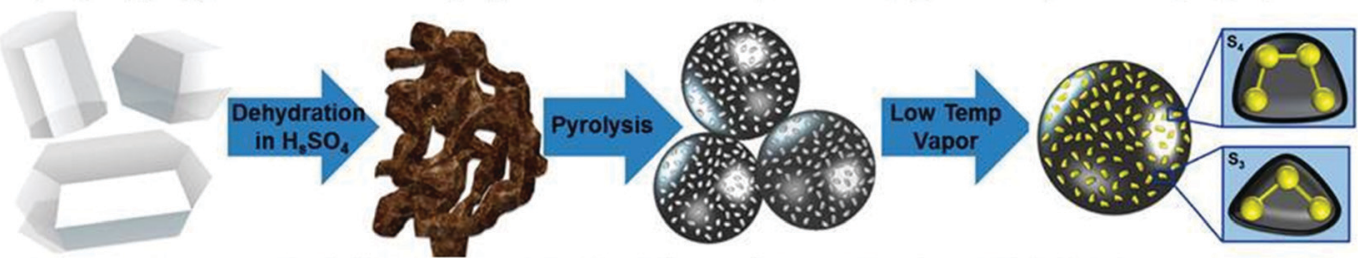

f)

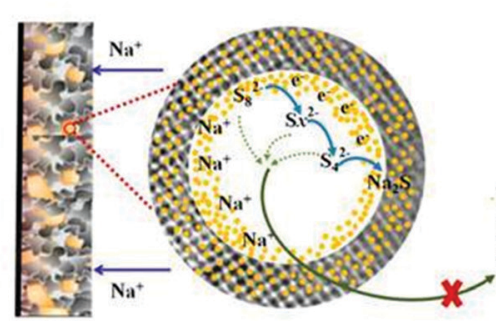

h)

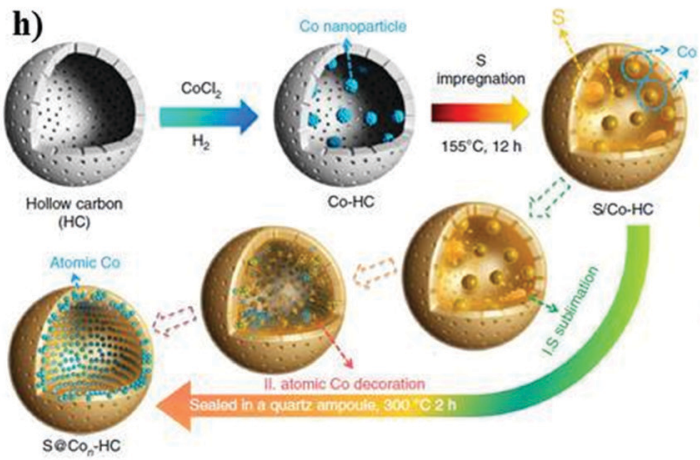

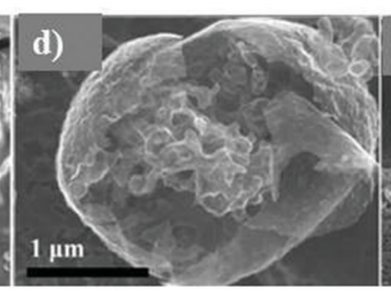

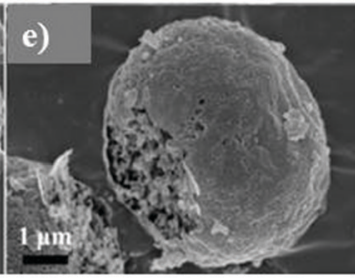

g)
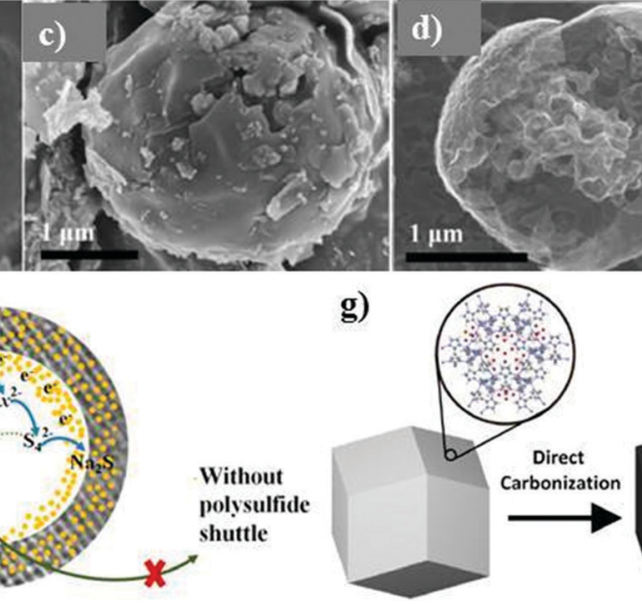

ZIF-8

i)

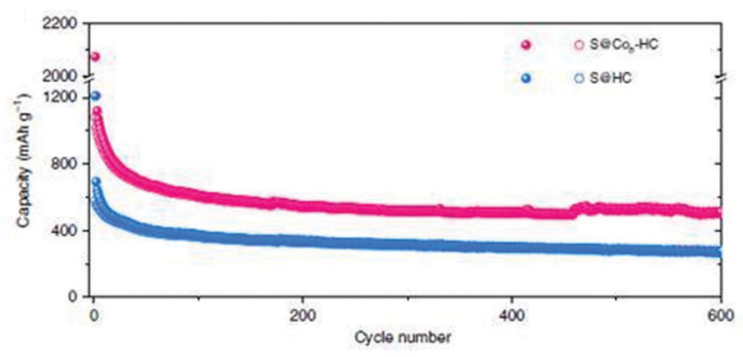

Fig. 9 (a) Schematic representation of the material processing steps using sucrose (sugar) to produce microporous sodium-sulfur battery cathodes. Reproduced with permission. ${ }^{117}$ Copyright 2017, the American Chemical Society. SEM images of (b) HCM, (c) HCMs-S, (d) PCM and (e) PCMs-S. Reproduced with permission. ${ }^{132}$ Copyright 2018, the American Chemical Society. (f) Schematic of the confinement in the S@iMCHS nanocomposite. Reproduced with permission. ${ }^{118}$ Copyright 2016, the American Chemical Society. (g) Procedure for the fabrication of C-ZIF-8/S. Reproduced with permission. ${ }^{133}$ Copyright 2016, The Royal Society of Chemistry. (h) Schematic illustration of the synthesis S@Con-HC. (i) Cycling performance of S@Con$\mathrm{HC}$ and SaHC. Reproduced with permission. ${ }^{70}$ Copyright 2018, Springer Nature.

carbon limits the loading of sulfur to under approximately $50 \mathrm{wt} \%$ due to its small size. ${ }^{123}$ Another potential solution to entrap or confine sulfur in a microporous 3D matrix can be achieved by engineering networks derived from metal organic frameworks (MOF). ${ }^{124-126}$ MOFs are a group of porous crystalline materials assembled by combining metal ions or clusters coordinated with organic linkers to form a highly ordered-porous spatial network. ${ }^{127-130}$ Wei's group pioneered the use of microporous carbon/sulfur as a 3D matrix for the sulfur cathode. ${ }^{131}$ The MOFderived template (i.e., ZIF-8) was synthesized via a high temperature carbonization process with a loading of about $1 \mathrm{mg} \mathrm{cm}{ }^{-2}$. By rationally tailoring the design, one can develop different MOF structures with prominent MOF matrices to encapsulate sulfur and physically entrap sodium polysulfides.
Other possible configurations of the $3 \mathrm{D}$ matrix to enhance the sulfur loading and concomitantly inhibit polysulfide dissolution have also been developed. One of these configurations was proposed by Lee et al., ${ }^{134}$ where they synthesized hollow carbon sphere/sulfur (HCS-S) with the sulfur content of about $56 \mathrm{wt} \%$ using a one-step hydrothermal method. The majority of the sulfur content was successfully impregnated within the ring-shaped hollow spheres. The cell could deliver a reversible capacity of $550 \mathrm{~mA} \mathrm{~h} \mathrm{~g}{ }^{-1}$. Zhang et al. contributed towards improving the battery performance by assembling porous carbon microspheres (PCMs) as a 3D matrix to support sulfur particles. ${ }^{132}$ Multi-dimensional framework PCMs were constructed as a doubleshell architecture with the outer carbon shell consisting of micronized-carbon shells and an inner carbon shell, with hollow 
carbon nanobeads. Elemental sulfur could be filled inside the porous carbon microspheres within the carbon shell, which was covered by the outermost part of the shell. Sulfur and its reaction intermediates were well-protected inside the double-shelled structure. There was about $28 \%$ sulfur embedded in the interconnected hollow carbon beads, and nearly $6 \%$ sulfur was inside the microspheres. Therefore, the double-shelled structure of the 3D matrix provided protection against direct contact with the electrolyte and mitigated polysulfide diffusion or dissolution in the electrolyte. A comparison was made with sulfur-filled hollow carbon microspheres (HCM), which could encapsulate about 44\% sulfur in its hollow structure. The SEM micrographs of HCM and PCM are shown in Fig. 9b-e for comparison. Upon cycling, the PCM matrix agglomerated and became much denser with micronized particles. Consequently, PCMs as the host in the sulfur cathode showed an excellent rate performance at various current densities ranging from $100 \mathrm{~mA} \mathrm{~g}^{-1}$ to $2000 \mathrm{~mA} \mathrm{~g}^{-1}$. Owing to the double-carbon shell architecture, the cathode exhibited an initial discharge capacity of $1100 \mathrm{~mA} \mathrm{~h} \mathrm{~g}{ }^{-1}$ and $795 \mathrm{~mA} \mathrm{~h} \mathrm{~g}^{-1}$ in the 2nd cycle and stabilized with the Coulombic efficiency of $63.6 \%$ in the 1 st cycle and $83.5 \%$ in the subsequent cycles. Xia et al. designed a 3D matrix to improve the sulfur loading and provide exceptional adsorption capability for sodium polysulfides. ${ }^{135}$ A hierarchical 3D matrix of porous carbon nanofibres constructed together with carbon hollow nanobubbles (CHNBs@PCNFs) was obtained via an electrospinning method. To activate the formation of homogeneously distributed porosity in the matrix, metal azides were used as both a bubbling and porogen reagent. The CHNB@PCNF/S cathode for the RT-Na/S battery delivered the 1st discharge capacity of about $1214 \mathrm{~mA} \mathrm{~h} \mathrm{~g}^{-1}$ at $0.1 \mathrm{C}$ and retained a remarkable reversible capacity of $786 \mathrm{~mA} \mathrm{~h} \mathrm{~g} \mathrm{~g}^{-1}$ after 50 cycles. The CHNB@PCNF/S cathode exhibited a high rate performance at various C-rates, including $0.1 \mathrm{C}, 0.2 \mathrm{C}, 0.5 \mathrm{C}, 1 \mathrm{C}$, and $2 \mathrm{C}$, which could be attributed to the high volume and surface area of PCNFs. CHNBs@PCNFs was regarded as an efficient building block to structurally integrate the 3D porous matrix. Efforts have been made to enhance the sulfur loading by exploring other structured matrices, e.g., mesoporous carbon. Wang et al. demonstrated an RT-Na/S battery using a mesoporous carbon hollow nanosphere/sulfur (iMCHS/S)-based sulfur cathode. ${ }^{118}$ The outer carbon shell could effectively trap sodium polysulfides, and the mesoporous shell could serve as a matrix to provide a conductive network for the sulfur particles. As depicted schematically in Fig. 9f, the interconnected mesoporous structure of the matrix could be loaded with a high amount of sulfur (about $4.1 \mathrm{mg} \mathrm{cm}^{-2}$ ). Due to the hollow interconnected mesoporous structures, sulfur could be encapsulated successfully. The as-developed cathode could deliver a reversible capacity of about $390 \mathrm{~mA} \mathrm{~h} \mathrm{~g}^{-1}$ and $127 \mathrm{~mA} \mathrm{~h} \mathrm{~g}^{-1}$ at a current density of $0.1 \mathrm{~A} \mathrm{~g}^{-1}$ and $5 \mathrm{~A} \mathrm{~g}^{-1}$, respectively. A reversible capacity of $292 \mathrm{~mA} \mathrm{~h} \mathrm{~g}^{-1}$ was retained even after 200 cycles of charge/discharge with about $\sim 88.8 \%$ capacity retention at a current density of $100 \mathrm{~A} \mathrm{~g}^{-1}$. Nonetheless, the cathode lacked stability in its structure and ability to confine the diffusion of polysulfides effectively.

With the assistance of certain dopants or metal clusters, the conductivity of materials can be greatly enhanced to offer strong confinement of sulfur species and sodium polysulfides. ${ }^{136-140}$ Nitrogen, as one of the best dopants, has been successfully used in Li-S batteries due to its excellent electron transfer properties and high electronegativity of 3.04. ${ }^{141-144}$ Chen's group synthesized a nitrogen-doped carbon composite matrix derived from zeolitic imidazolate framework-8 (ZIF-8). ZIF-8 represents a class of MOFs with a sodalite-type structure and regular mesoporous/ microporous pore sizes. MOF-derived nitrogen-doped 3D matrices are of particular interest due to their simple fabrication process and reproducibility. Carbonized ZIF/S (cZIF/S) was fabricated via a melt diffusion method, resulting in the successful infusion of sulfur chains inside the nitrogen-doped cZIF-8 framework with $50 \%$ S-content, as shown in Fig. $9 \mathrm{~g}$. The cathode could be cycled for over 250 cycles with a reversible capacity of $500 \mathrm{~mA} \mathrm{~h} \mathrm{~g}{ }^{-1}$ at $0.2 \mathrm{C}$. The $\mathrm{cZIF} / \mathrm{S}$ composite exhibited a good rate performance with C-rates ranging from $0.1 \mathrm{C}$ to $2 \mathrm{C}$. The high rate performance could also be attributed to the addition of nitrogen dopant in the carbon framework, which facilitates: (1) the formation of covalent bonds with sulfur, (2) sulfur immobilization, (3) chemical bonding between sulfur and the oxygen functional groups in the carbon framework and (4) chemical adsorption of sulfur in the carbon matrix. The strong chemical bonding of sulfur with the oxygen functional groups of carbon was revealed using XPS. The sulfur loading achieved was about $0.7-0.9 \mathrm{mg} \mathrm{cm}^{-2}$, which is quite low and it may impede the system from reaching a high specific energy density. ${ }^{133}$ Exploiting the advantages of the porous structure of MOFs, in 2020, Xiao et al. ${ }^{145}$ proposed another MOF-based sulfur and nitrogen-doped porous carbon as a host. A Zn-derived MOF with 2,5-thiophenedicarboxylic acid and 1,4-bis(pyrid-4-yl)benzene as the ligands and a vapor-infiltration method were considered for efficiently infiltrating sulfur within the carbon matrix with strong covalent bonding. The composite cathode with a polydopamine coating and 37\% S-content and $0.9-1.5 \mathrm{mg} \mathrm{cm} \mathrm{cm}^{-2}$ S-loading could deliver an initial discharge capacity of $1003 \mathrm{~mA} \mathrm{~h} \mathrm{~g}^{-1}$ at $0.1 \mathrm{~A} \mathrm{~g}^{-1}$ and a reversible capacity of $680 \mathrm{~mA} \mathrm{~h} \mathrm{~g}^{-1}$ at $1 \mathrm{~A} \mathrm{~g}^{-1}$ after 500 cycles. A 3D hierarchical morphology nanocomposite with different sulfur loadings of $25,45,65$, and $86 \mathrm{wt} \%$ in nitrogen-doped graphene nanosheets was prepared recently. ${ }^{146}$ The 3D morphology of the composite resembled a voile structure, which confined the discharge products effectively to alleviate the shuttle effect. They concluded that the S-loading of $25 \mathrm{wt} \%$ displayed the best performance with an initial discharge capacity of $212 \mathrm{~mA} \mathrm{~h} \mathrm{~g}{ }^{-1}$ and $136 \mathrm{~mA} \mathrm{~h} \mathrm{~g}^{-1}$ in the 10 th cycle, which can be attributed to the ease of the intercalation of sodium ions. However, despite this, the partial dissolution of sodium polysulfides was observed during cycling even with the lowest loading of $25 \mathrm{wt} \%$. The performance of the electrode material deteriorated with an increase in the sulfur loading; therefore, composites with a higher loading are needed given that they may enhance the energy density of the cell. Qiang et al. reported a nitrogen-doped porous carbon 3D matrix for the sulfur cathode to boost the cycle-life of RT-Na/S batteries. ${ }^{147}$ Doped-hierarchical-structured porous-based sulfur (N,S-HPC/S) was fabricated as a cathode material. The sulfur molecules could be effectively trapped within the porous carbon through a calcination process followed by melt diffusion. The sulfur loading of about $1.1 \mathrm{mg} \mathrm{cm} \mathrm{cm}^{-2}$ could be achieved in this architecture. 
The presence of nitrogen improved the electrostatic interaction between the matrix and sodium polysulfides, which enhanced the entrapment of sodium polysulfides to inhibit side reactions. Guo et al. reported the synthesis of a unique 3D matrix of nickel concatenated by nitrogen doped on carbon fibres (NCFs) via an electrostatic spinning method. ${ }^{140}$ Each unit of nickel displayed a hollow morphology and could successfully buffer the volume changes during the charge-discharge cycles and also provide polar interactions bonds between $\mathrm{Ni}$ and $\mathrm{S}$ upon S-loading. Nickel, in combination with NCFs as the host for the S-cathode, exhibited a high rate capability ranging from $0.2 \mathrm{C}$ to $5 \mathrm{C}$ with a reversible capacity of 738.7 and $181.7 \mathrm{~mA} \mathrm{~h} \mathrm{~g}{ }^{-1}$, respectively. In addition, the cathode could maintain the 1st discharge capacity of $\sim 431 \mathrm{~mA} \mathrm{~h} \mathrm{~g}^{-1}$ and $\sim 233 \mathrm{~mA} \mathrm{~h} \mathrm{~g}{ }^{-1}$ after 270 cycles at $1 \mathrm{C}$ due to the high catalytic effect of the nickel units. However, despite the intriguing rate performance, the cathode could maintain an area loading of only about $0.5-0.7 \mathrm{mg} \mathrm{cm}^{-2}$. Another approach to enhance the loading of sulfur and prevent the dissolution of polysulfides was proposed by Zhang and co-workers. ${ }^{70}$ They used atomic cobalt as an effective electro-catalyst to accelerate the conversion reactions. As schematically illustrated in Fig. 9h, atomic cobalt and the elemental sulfur particles were efficiently encapsulated within the hollow framework of the porous carbon nanoparticles. A sulfur loading as high as $5 \mathrm{mg} \mathrm{cm}^{-2}$ could be achieved. Electron microscopy revealed uniformly dispersed atomic cobalt and sulfur particles within the carbon nanoparticles. The hollow carbon and atomic cobalt could effectively trap and bind with polysulfides, respectively, to improve the stability of the cell for over 600 cycles at a current density of $100 \mathrm{~mA} \mathrm{~g}^{-1}$, as shown in Fig. 9i.

To effectively harness the benefits of the transition metal sulfides to accelerate the reversible reactions, while controlling the diffusion of polysulfides in the electrolyte solution, Meyerson et al. ${ }^{148}$ reported a molybdenum sulfide-based sulfur cathode with

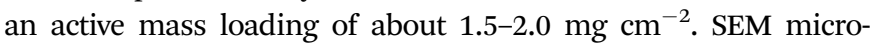
graphs were captured for the as-developed molybdenum sulfide (i.e., $\operatorname{MoS}_{5.6}$ ) before cycling, showing angular-shaped particles of several micrometers. After ten cycles, the angular-shaped particles transformed into spherical structures particles with a reduced lateral size (see Fig. 10a-d). However, although the transformation of the angular-shaped particles into spherical particles increased the accessibility of sodium ions into the sodiation active sites, cracks were observed during long-term cycling. The $\mathrm{MoS}_{5.6}$ electrode showed a capacity of $537 \mathrm{~mA} \mathrm{~h} \mathrm{~g}^{-1}$ and $200 \mathrm{~mA} \mathrm{~h} \mathrm{~g}^{-1}$ at current densities of $50 \mathrm{~mA} \mathrm{~g}^{-1}$ and $1 \mathrm{~A} \mathrm{~g}^{-1}$, respectively.

Recently, Yan et al. ${ }^{139}$ examined a nitrogen-doped porous carbon network to embed nickel sulfide nanocrystals as the sulfur cathode for RT-Na/S batteries. A high content of about $56 \%$ of sulfur in $\mathrm{NiS}_{2} @ N P C T s / S$ or a sulfur loading of about $2.5 \mathrm{mg} \mathrm{cm}^{-2}$ was achieved. The existence of two different types of sulfur atoms was confirmed by X-ray photoelectron spectroscopy (XPS). Due to the sulfur loading, NiS $\mathrm{N}_{2} @ N P C T s / S$ as the cathode material exhibited distinct plateaus with a high capacity of $960 \mathrm{~mA} \mathrm{~h} \mathrm{~g}{ }^{-1}$ in the 1 st cycle, which remained stable at $410 \mathrm{~mA} \mathrm{~h} \mathrm{~g}{ }^{-1}$ after 750 cycles, as shown in Fig. 10e. The high performance and increased sulfur loading were attributed to the
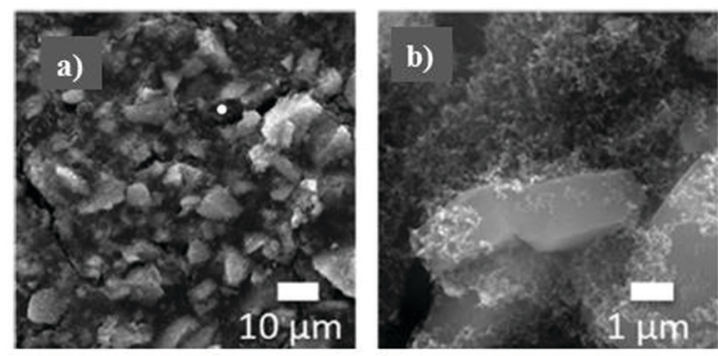

e)

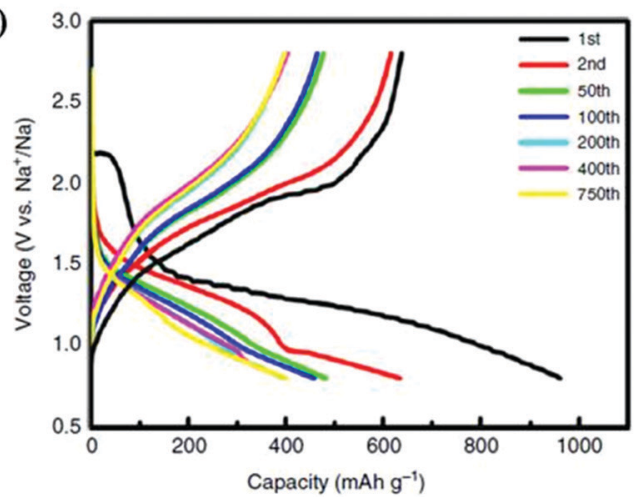

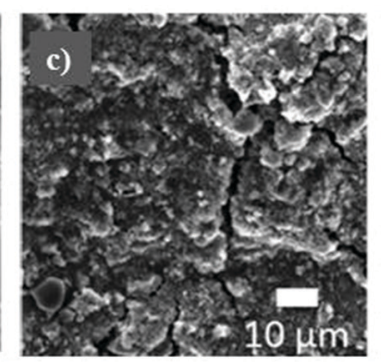
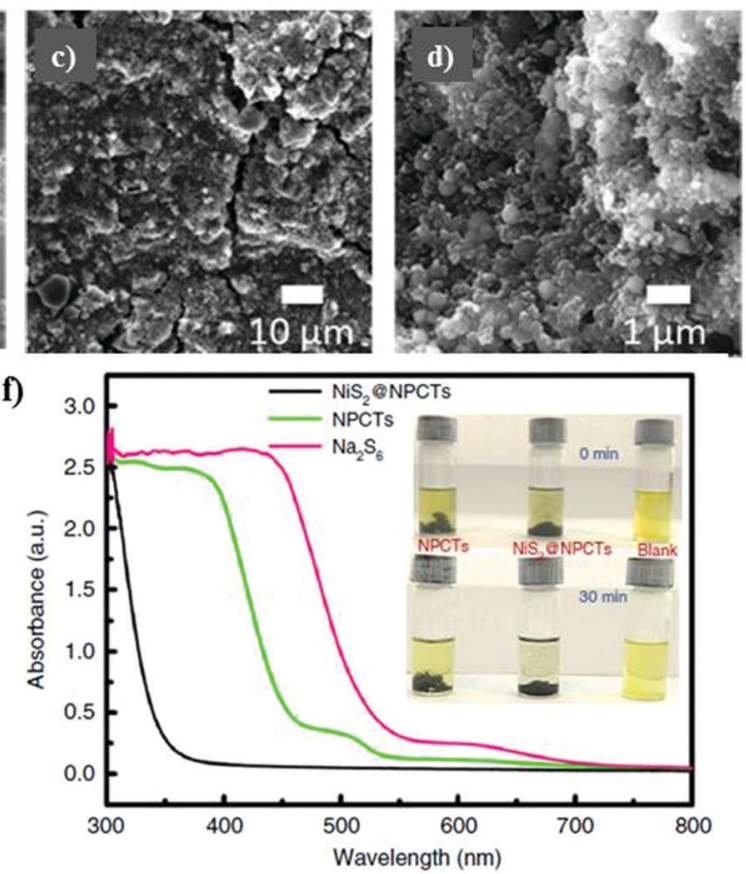

Fig. 10 Scanning electron micrographs of the $\mathrm{MoS}_{5.6}$ electrode ( $\mathrm{a}$ and b) before cycling and (c and d) after 10 cycles at $50 \mathrm{~mA} \mathrm{~g}{ }^{-1}$. Reproduced with permission. ${ }^{148}$ Copyright 2020, the American Chemical Society. (e) Corresponding charge/discharge profiles of NiS ${ }_{2}(\mathrm{NPCTs} / \mathrm{S}$ at different cycles. (f) Ultraviolet/visible (UV-vis) spectra and corresponding photographs (inset) of pure $\mathrm{Na}_{2} \mathrm{~S}_{6}$ solution and the solution after exposure to NiS $\mathrm{NNPCTs}_{2}$ and NPCTs. Reproduced with permission. ${ }^{139}$ Copyright 2019 Springer Nature. 
synergistic effects of the transition metal sulfide with $\mathrm{N}$-doped carbon network, which was confirmed by the UV visible spectra, as shown in Fig. 10f. However, although the cathode based on the $\mathrm{N}$-doped 3D matrix could maintain an impressive cycling performance and relatively high sulfur loading, irreversible losses in the capacity were observed. Aslam and co-workers studied a polar metal chalcogenide as a matrix for the sulfur cathode in the RT-Na/S battery. ${ }^{116}$ A bipyramidal prism structure of cobalt sulfide was fabricated via simple reflux, as shown in Fig. 11a. A high sulfur content of about $64.5 \%$ or a sulfur loading of about $4.4 \mathrm{mg} \mathrm{cm}^{-2}$ could be obtained through this method. In contrast to the non-polar sulfur matrix, the polar matrix could physically block the outward diffusion of sodium polysulfides. The sulfur and its reduced products could be successfully entrapped through the polar sites and wide hollow cavity architecture, as depicted schematically in Fig. $11 \mathrm{~b}$ and c. The $\mathrm{CoS}_{2} / \mathrm{C}$ (BPCS) cathode exhibited an interweaving hierarchical architecture with wide internal hollow spaces of about $376 \mathrm{~nm}$ to entrap the polysulfides. BPCS displayed a high discharge capacity of $1347 \mathrm{~mA} \mathrm{~h} \mathrm{~g}^{-1}$ in the 1 st cycle, and $755 \mathrm{~mA} \mathrm{~h} \mathrm{~g}^{-1}$ in the 2 nd cycle, and $701 \mathrm{~mA} \mathrm{~h} \mathrm{~g}^{-1}$ after 350 cycles with a high coulombic efficiency of $98.5 \%$. The sulfur loadings of about $7.3 \mathrm{mg} \mathrm{cm} \mathrm{cm}^{-2}$ and $9.1 \mathrm{mg} \mathrm{cm}^{-2}$ were also obtained, and the sulfur cathode was cycled at a rate of $0.5 \mathrm{C}$, where the 1 st areal capacity of about $6.24 \mathrm{~mA} \mathrm{~h} \mathrm{~cm} \mathrm{~cm}^{-2}$ and $8 \mathrm{~mA} \mathrm{~h} \mathrm{~cm}{ }^{-2}$ was achieved, respectively. Simultaneously, they retained a capacity of $5.5 \mathrm{~mA} \mathrm{~h} \mathrm{~cm} \mathrm{~cm}^{-2}$ and $6.6 \mathrm{~mA} \mathrm{~h} \mathrm{~cm}{ }^{-2}$ after ten cycles, respectively. The $\mathrm{CoS}_{2} / \mathrm{C}$ cathode presented a new reaction pathway to facilitate the reduction process from $\mathrm{S}$ to $\mathrm{Na}_{2} \mathrm{~S}$ by mitigating the dissolution of sodium polysulfides in the electrolyte. Therefore, this may diminish the

a)

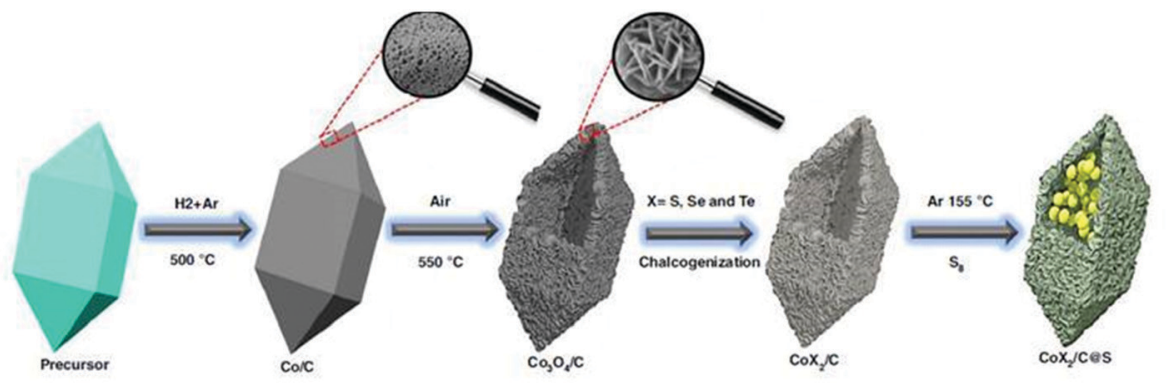

b)

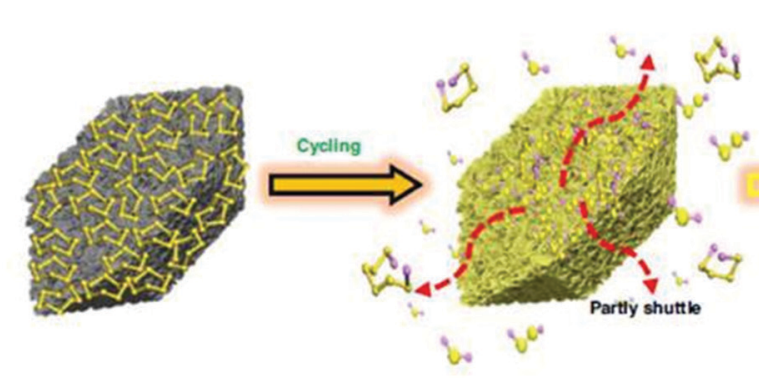

c)
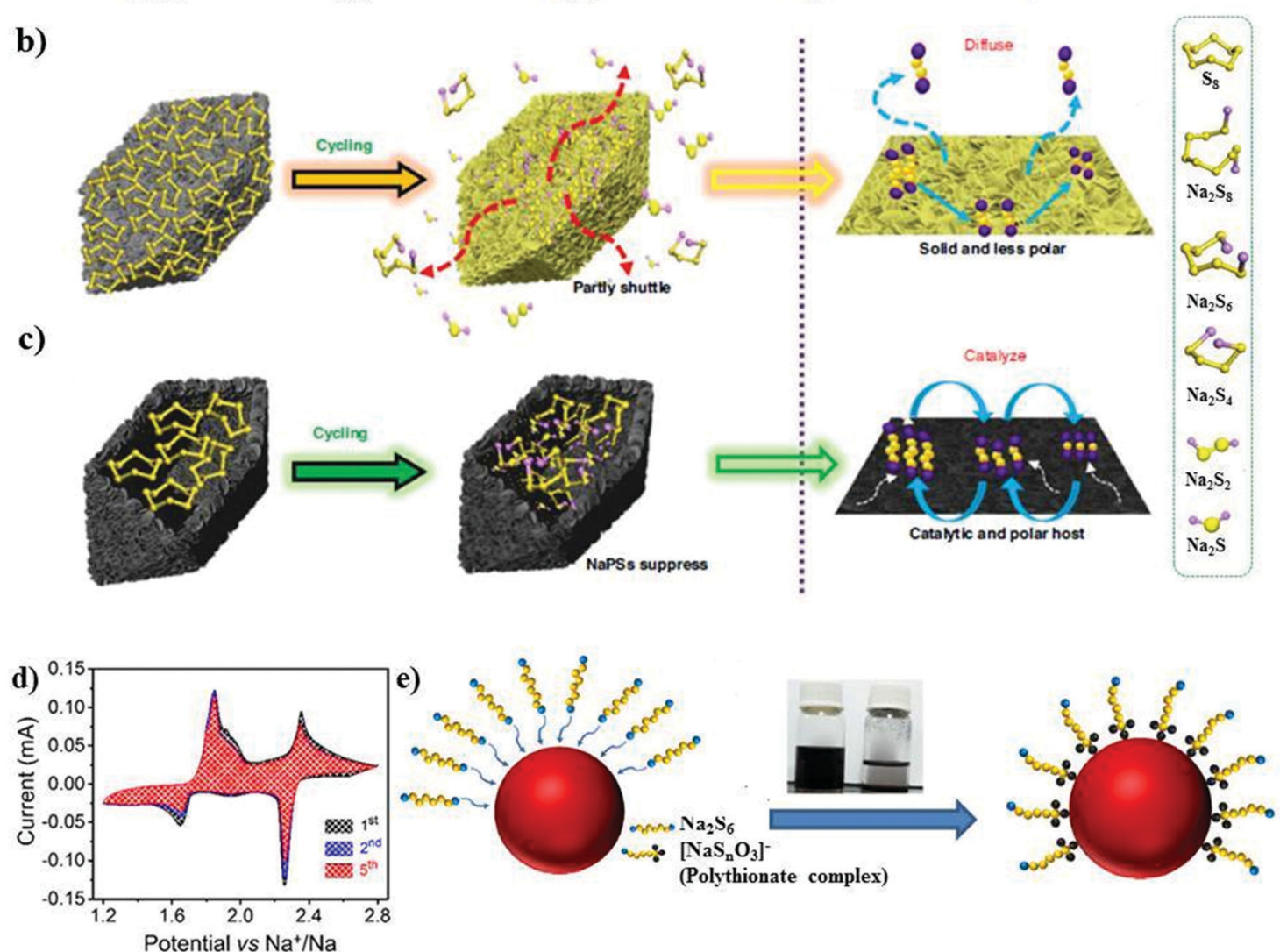

Fig. 11 (a) Synthesis of metal chalcogenide SABPCX composites. (b) Diffusion of NaPSs in solid nonpolar host. (c) Suppression of NaPSs in hollow polar/ catalytic host. Reproduced with permission. ${ }^{116}$ Copyright 2020, Springer Nature. (d) Cyclic voltammetry curves of the rGO/S/Mn $\mathrm{O}_{y} @ \mathrm{aSA}-\mathrm{PANI}$ cathode at a scan rate of $20 \mu \mathrm{V} \mathrm{s}^{-1}$. (e) Schematic of the possible surface redox reaction between $\mathrm{Na}_{2} \mathrm{~S}_{6}$ and $\mathrm{Mn}_{x} \mathrm{O}_{y}$. Reproduced with permission. ${ }^{61}$ Copyright 2019, the American Chemical Society. 
shuttle effect to provide better electrochemical performance even with a higher sulfur loading.

One of the issues of increasing the thickness of the sulfur loading is the rapid dissolution of sulfur products due to the drop in the capillary pressure. ${ }^{119}$ In addition, a restricted reaction pathway for sodium ions and electrons, and dramatic volumetric changes are observed with an increased loading. Thus, rationally reinforcing different composites of reduced graphene oxide (rGO) and manganese oxide $\left(\mathrm{Mn}_{x} \mathrm{O}_{y}\right)$ with $\mathrm{Na}$ alginate/polyaniline hybrid binder to form a 3D matrix may be another effective approach to mitigate these issues. ${ }^{61}$ To design this type of interconnected 3D matrix, Ghosh and co-workers designed a $\mathrm{rGO} / \mathrm{S} / \mathrm{Mn}_{x} \mathrm{O}_{y} @ S A-P A N I$ composite cathode via a vacuum filtration method, which resulted in a sulfur loading of about $2.05 \mathrm{mg} \mathrm{cm}^{-2}$. Owing to the good electrical conductivity of rGO $\left(4.8 \times 10^{3} \mathrm{~S} \mathrm{~m}^{-1}\right)$ and cubic lattice structure of the $\mathrm{Mn}_{x} \mathrm{O}_{y}$ nanoparticles, the as-synthesized 3D conductive matrix with porous interconnected morphology could accommodate volume fluctuations during the reversible sodiation and desodiation reactions. Cyclic voltammetry was performed using the composite cathode, as shown in Fig. 11d, showing a series of cathodic peaks in the range of $1.2-2.8 \mathrm{~V} v s$. $\mathrm{Na} / \mathrm{Na}^{+}$, corresponding to: (1) the conversion of solid-phase $S_{8}$ to liquid-phase long-chain polysulfides, (2) long-chain polysulfides to liquid-phase middle-chain polysulfides, and (3) middle-order polysulfides to insoluble short-chain polysulfides, respectively. The charge/discharge curve for the composite cathode showed an enhanced performance in the 1st, 2nd and 5th cycles at a current density of $0.2 \mathrm{~A} \mathrm{~g}^{-1}$. As a result of the enhanced ionic-electron distribution efficiency, the diffusion pathways of sodium ions and electrons could be shortened, contributing to the improved conversion reactions with minimal dissolution of polysulfides. In addition, $\mathrm{Mn}_{x} \mathrm{O}_{y}$ nanoparticles could act as a reducing agent for polysulfides, resulting in a high affinity of $\mathrm{Mn}_{x} \mathrm{O}_{y}$ nanoparticles (30-50 nm) towards $\mathrm{Na}_{2} \mathrm{~S}_{6}$, which is evident in Fig. 11e. The sulfur cathode comprised of $\mathrm{rGO} / \mathrm{S} / \mathrm{Mn}_{x} \mathrm{O}_{y} @ \mathrm{SA}-\mathrm{PANI}$ could deliver a remarkable

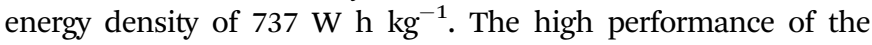
cathode was attributed to the electrocatalytic activity of the $\mathrm{Mn}_{x} \mathrm{O}_{y}$ nanoparticles and the conductive nature of the rGO/S/Mn $\mathrm{M}_{y} @ \mathrm{SA}-$ PANI composites. However, with an increase in the number of cycles, a gradual decay was observed in the reversible capacities, which could be due to the formation of a thick SEI on the surface of the anode, affecting the dissolution and deposition of sodium ions.

The inhomogeneous distribution of sulfur within the matrix often leads to the low utilization of sulfur, which has become a roadblock to reach the unprecedented specific capacity of the RT-Na/S battery. ${ }^{134,149,150}$ In the pursuit of developing an ideal host for elemental sulfur and confining the polysulfides, researchers have reported different composites in various structures, which have been found to be suitable for achieving a high sulfur loading cathode. One unique contribution was reported by $\mathrm{Yu}$ and Manthiram, where they explored different sodium/polysulfide batteries based on different composite materials. ${ }^{151}$ They designed a cathode composed of long-chain sodium polysulfides with high surface area multi-walled carbon nanotube (MWCNT) fabric, which served as the current collector for the sulfur cathode.
The cycling performance of the dissolved liquid-phase NaPS catholyte/MWCNT with $60 \%$ sulfur content was investigated at a discharge cut-off voltage of $1.2 \mathrm{~V}$ for 30 cycles, which maintained a capacity of about $400 \mathrm{~mA} \mathrm{~h}^{-1}$. NaPSs/MWCNT exhibited a sharp decay in capacity after the first few cycles, which could be due to the sluggish reversibility of the sodium polysulfides after the charge/discharge cycles. By varying the concentration of the sodium polysulfide catholyte in the composite material, the sulfur loading could be further enhanced. Therefore, Yu et al. performed further studies, but this time with short-chain polysulfides $\left(\mathrm{Na}_{2} \mathrm{~S}\right)$ (80\%), which were spread on MWCNT (20\%) to enhance the conductivity of the insulated $\mathrm{Na}_{2} \mathrm{~S} .{ }^{152} \mathrm{Na}_{2} \mathrm{~S}$, as they claimed, possesses "high electronic resistivity and low sodium ion diffusivity," behaving as a special cathode with a high anchoring effect that is enough to encapsulate the charge/discharge products during the cycling process. The cell with the $\mathrm{Na}_{2} \mathrm{~S}$ composite cathode was tested at two different $\mathrm{C}$-rates with a discharge capacity of $660 \mathrm{~mA} \mathrm{~h} \mathrm{~g}^{-1}$ at $\mathrm{C} / 10$ and $540 \mathrm{~mA} \mathrm{~h} \mathrm{~g}{ }^{-1}$ at $\mathrm{C} / 3$. The cell exhibited a cycle life of about 50 cycles, retaining capacities of $560 \mathrm{~mA} \mathrm{~h} \mathrm{~g}^{-1}$ and $380 \mathrm{~mA} \mathrm{~h} \mathrm{~g}{ }^{-1}$, and a Coulombic efficiency of $\sim 90 \%$ after the subsequent cycles. As a result of its unique architecture with good electron-ionic transport, the $\mathrm{Na}_{2} \mathrm{~S} / \mathrm{MWCNT}$ electrode exhibited an energy density of $\sim 250 \mathrm{~W} \mathrm{~h} \mathrm{~kg}^{-1}$. However, the cell experienced high polarization with an increase in rate due to the inert nature of $\mathrm{Na}_{2} \mathrm{~S}$. In another contribution, they proposed a conductive matrix of carbon nanofibres anchored with high surface area activated carbon. ${ }^{153}$ The sulfur content of about 40-50 wt\% could be accommodated within this matrix. CNF/AC was utilized as the matrix for the sodium polysulfide cathode to enhance the utilization of sulfur in the polysulfides. Recently, Bloi and co-workers revisited this configuration using nanostructured $\mathrm{Na}_{2} \mathrm{~S}$ (90 wt\%) with conductive carbon as the matrix for the sulfur cathode. ${ }^{154}$ The $\mathrm{Na}_{2} \mathrm{~S} / \mathrm{C}$ hybrid cathode, which was synthesized via carbothermal reduction at different temperatures, showed improved cathode utilization with enhanced stability and an initial discharge capacity of about $740 \mathrm{~mA} \mathrm{~h} \mathrm{~g}{ }^{-1}$. One of the methods to achieve a higher and stronger adsorption of polysulfides can be realized by incorporating $\mathrm{Na}_{2} \mathrm{~S}_{6}$ catholyte into a carbon cloth/ $\mathrm{MnO}_{2}$ nanoarray. ${ }^{155}$ Carbon cloth/ $\mathrm{MnO}_{2}$ showed a strong anchoring effect towards higher-order polysulfides, alleviating the shuttle effect and accelerating the reversibility and reaction kinetics. A sulfur loading of about $1.7 \mathrm{mg} \mathrm{cm}{ }^{-2}$ was attained. The $\mathrm{CC} / \mathrm{MnO}_{2} @ \mathrm{Na}_{2} \mathrm{~S}_{6}$ cathode displayed an initial specific capacity of $\sim 938 \mathrm{~mA} \mathrm{~h} \mathrm{~g}{ }^{-1}$ with $67 \%$ retention after 500 cycles. Table 1 comprehensively summarizes the efforts made hitherto to enhance the sulfur loading and the cell performance. Despite the advantages offered by the judicious combination of different composite materials, dedicated efforts are still required to engineer matrix materials for the sulfur cathode.

\section{Status of Na metal anode and electrolyte engineering}

Owing to its high theoretical capacity (1166 $\mathrm{mA} \mathrm{h} \mathrm{g}^{-1}$ ), low electrochemical potential $(-2.71 \mathrm{~V})$ with respect to the standard hydrogen electrode, high abundance and cost effectiveness, the 


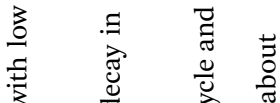
$\stackrel{\infty}{G} \tilde{b}$

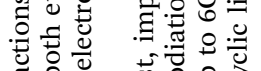

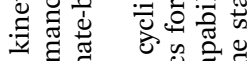

o.

焉券

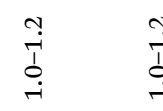
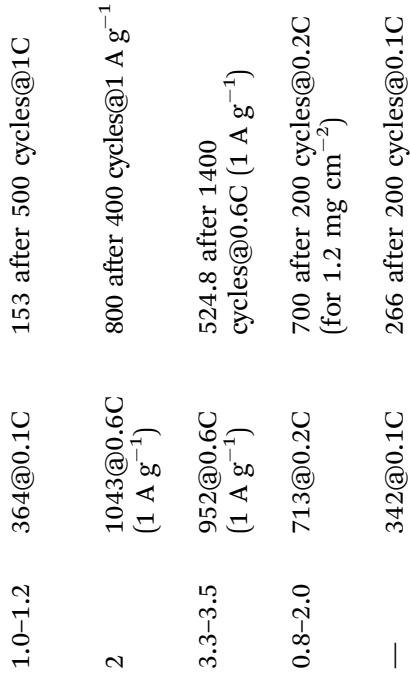


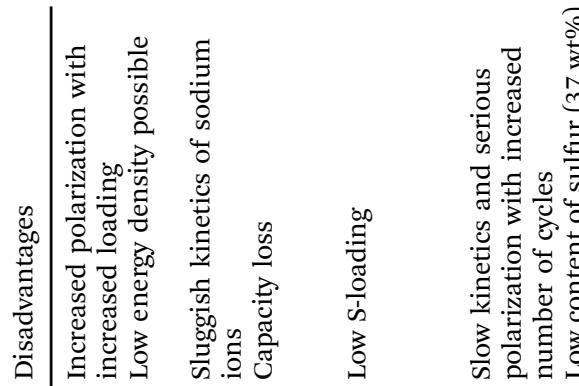

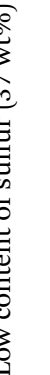
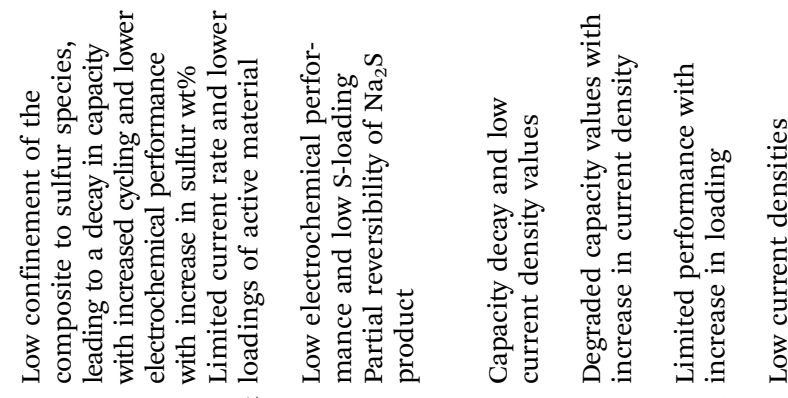

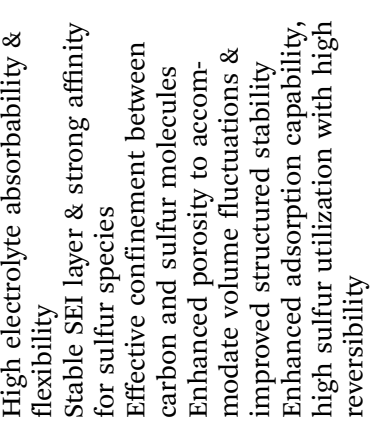

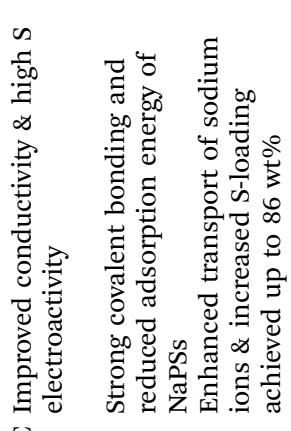

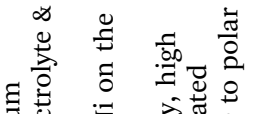

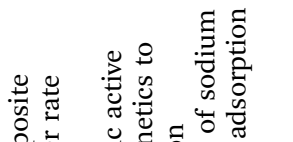

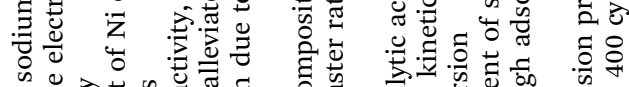

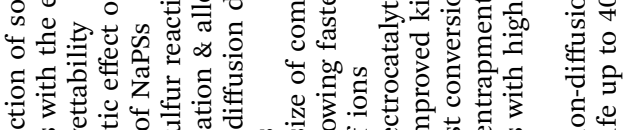

$\because 00$

:

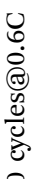

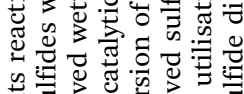

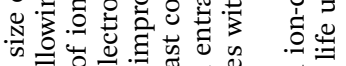

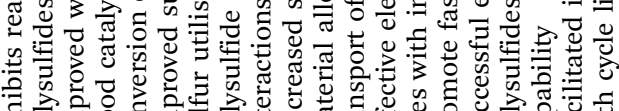

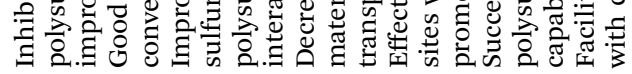

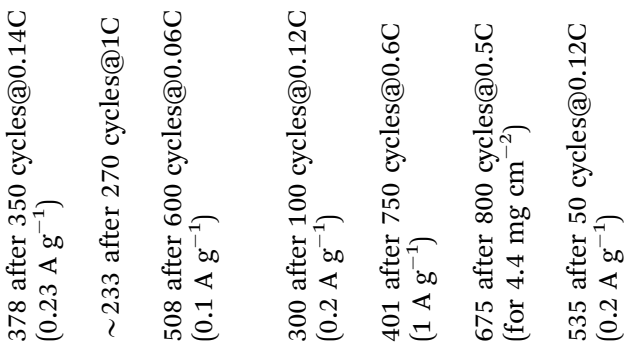

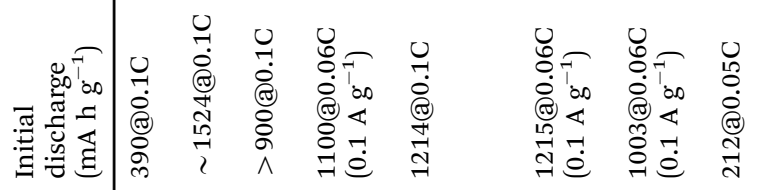

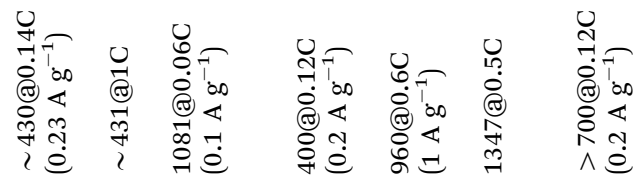

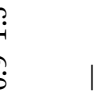

$\begin{array}{ccc}- & \hat{1} \\ 0 & 0 & 0 \\ 1 & 0\end{array}$

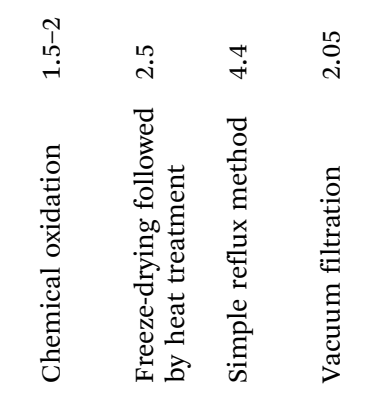

$\rightarrow+\infty \mid$

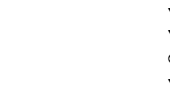

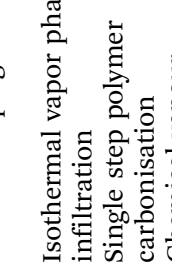

A 政

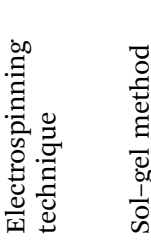

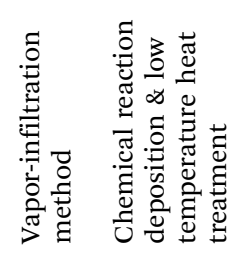

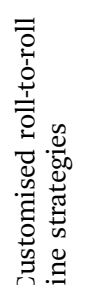

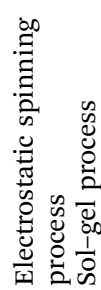

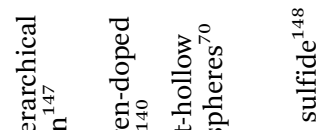

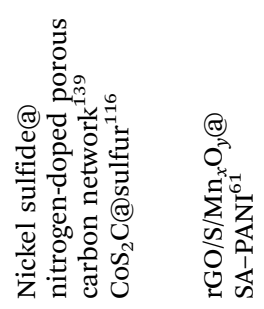


sodium anode is considered an appealing candidate as an anode for RT-Na/S batteries. ${ }^{156,157}$ However, there are numerous challenges that need to be addressed urgently, which include, but are not limited to the following;

(1) Rapid chemical reactivity of Na metal with electrolyte. ${ }^{158}$ This leads to the decomposition of the electrolyte on the metal surface, which creates a layer of by-products, and the instability of this layer (solid electrolyte interphase) ultimately results in a decay in performance.

(2) Growth of dendrites. ${ }^{159,160}$ They are mostly caused because of surface protrusions, uneven distribution of current density and non-uniform deposition of $\mathrm{Na}$, which result in the continuous growth of metal dendrites, eventually, short circuiting the system.

(3) Gas evolution. ${ }^{161}$ The formation of dendrites is one of the main reasons for gas evolution, which accumulates gradually upon the reaction between electrolyte and metal dendrites.

(4) Volume fluctuations. ${ }^{162,163}$ This can occur because of the increase or decrease in the thickness of the deposits, resulting in increased pressure and mechanical stresses.

Thus far, various strategies have been employed to stabilize the $\mathrm{Na}$ metal anode. For instance, Gu et al. ${ }^{164}$ reported an electrochemical surface polishing approach to achieve an ultra-smooth and ultra-thin SEI for an Na metal anode with an organic/inorganic rich multilayer structure. Jiao et al. ${ }^{165}$ proposed an implantable artificial protective layer to stabilize an $\mathrm{Na}$ metal anode obtained via the doctor-blade coating layer technique, where NaF particles were added to an N-methyl pyrrolidone (NMP) and polyvinylidene fluoride (PVDF) solution, giving a thickness of $20 \mu \mathrm{m}$. Zhao's group $^{166}$ reported the rational design of carbon paper (CP) with $\mathrm{N}$-doped carbon nanotubes (CNTs) for Na deposition as a 3D host that can accommodate $\mathrm{Na}$ ions. Owing to the good conductivity and high surface area of $\mathrm{CP}$, it was used as a skeleton and the $\mathrm{N}$-doped CNTs effectively reduced the contact angle between the
Na metal and host. Thus far, electrolyte engineering is the simplest technique to form a nearly ideal artificial solid electrolyte interphase (SEI), where the reaction between the engineered electrolyte and Na metal plays a decisive role. An ideal electrolyte should possess some characteristic attributes such as: (i) good ionic conductivity $\left(1-10 \mathrm{mS} \mathrm{cm}^{-1}\right)^{167,168}$ to allow easy access to sodium ions, (ii) wide potential window (1.5-4.2 V vs. $\left.\mathrm{Na} / \mathrm{Na}^{+}\right),{ }^{169}$ (iii) not actively participate in the chemical reaction with a stabilized electrolyte-electrode interfacial contact, (iv) electrochemical compatibility with the components of the battery system and must be inflammable, and (v) cost-effective and environmental benignancy. ${ }^{33,170}$ Nevertheless, the aforementioned attributes can be challenging due to the instability of most of organic electrolytes in the presence of alkali metal anodes, resulting in the formation of a highly uncontrolled solid electrolyte interface (SEI). ${ }^{171}$ Thus, continuous research to engineer the electrolyte has been put forward to achieve most of the desirable properties. It should be noted that it is crucial to establish an electrolyte system with a suitable solvent, long-term stable sodium salts and additives to ensure the formation of a mechanically and chemically stable SEI. ${ }^{172,173}$ The progress made in electrolyte engineering is still in its infancy and highly limited due to its high corrosivity, narrow thermal stability window of the additives and sodium salts, besides their thermodynamic instability in the presence of Na metal.

The concept of designing localized metal-alloy artificial interfaces is relatively new, which exhibits tremendous potential to boost the stability of alkali metal anodes. Recently, Zheng's group $^{174}$ devised a new strategy to intrinsically develop a localized metal-alloy interphase. The electrolyte was engineered by adding a controlled amount of additive such as $\mathrm{SnCl}_{2}$ to achieve the in situ emergence of an $\mathrm{Na}-\mathrm{Sn}$ alloy interphase directly over the $\mathrm{Na}$ metal anode, as shown in Fig. 12a. The interphase was (a)

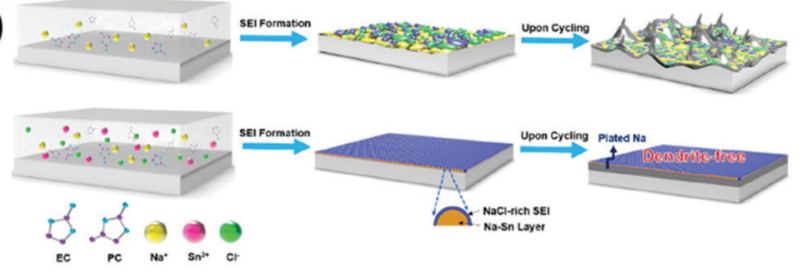

(c)
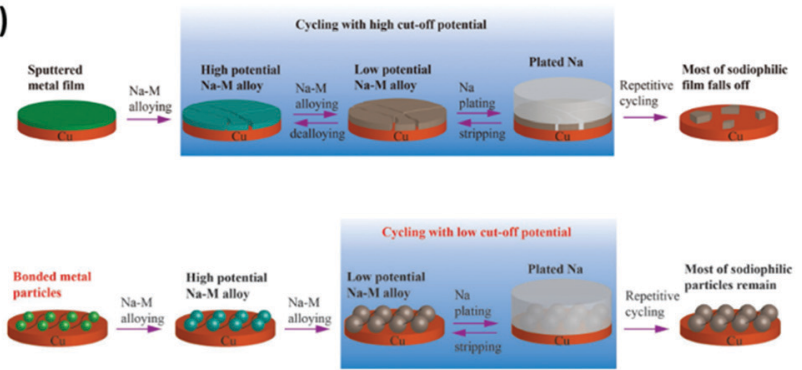

(b)
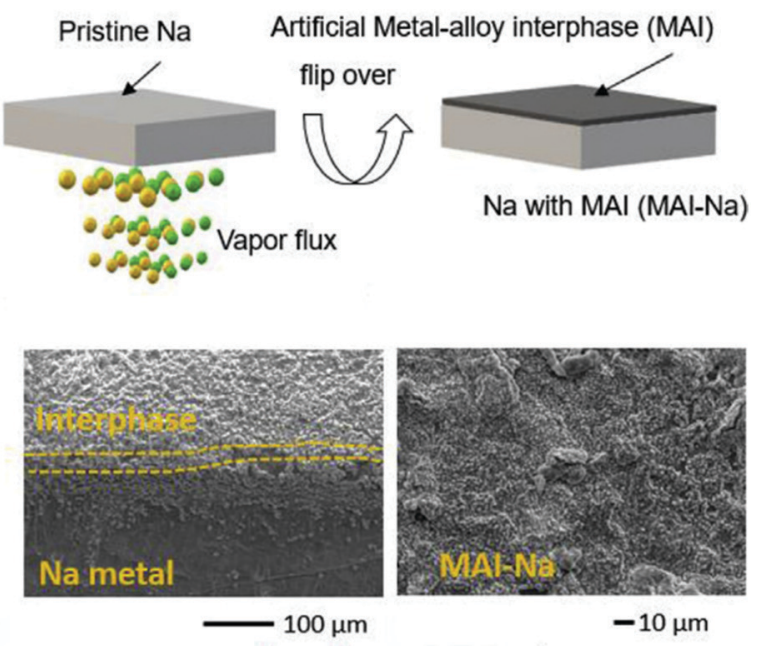

Fig. 12 (a) Schematic of SEl generation on Na metal working in a traditional carbonate-based electrolyte, leading to dendrite growth and in situ-formed $\mathrm{NaCl}$-rich SEI with $\mathrm{Na}-\mathrm{Sn}$ alloy layer, resulting in uniform ion transport and dendrite-free cycling. Reproduced with permission. ${ }^{174}$ Copyright 2019 , the American Chemical Society. (b) Schematic representation of process involved in forming an artificial metal alloy interphase and corresponding SEM images. Reproduced with permission. ${ }^{175}$ Copyright 2020, Elsevier. (c) Cycling with high cut-off potential, leading to most of the sodiophilic films falling off and cycling with low cut-off potential leads to the retention of most of the sodiophilic particles. Reproduced with permission. ${ }^{176}$ Copyright 2019 , John Wiley and Sons. 
considered to result from the electrochemical reactions between $\mathrm{SnCl}_{2}$ and $\mathrm{Na}$ metal, where $\mathrm{SnCl}_{2}$ is reduced to $\mathrm{Sn}$ and forms an alloy with $\mathrm{Na} .{ }^{177,178}$ A dendrite free anode and stable cycling were achieved for $500 \mathrm{~h}$ with $50 \mathrm{mM} \mathrm{SnCl}_{2}$ added to the EC/PC electrolyte, showing an improved performance compared to the $\mathrm{Na}_{3} \mathrm{~V}_{2}\left(\mathrm{PO}_{4}\right)_{3}$ (NVP) cathode. Although the stability of the anode improved, the deposition morphology appeared to be highly nonuniform. Thus, to design and develop a controlled and highly uniform metal-alloy interphase, an innovative methodology was proposed recently. ${ }^{175}$ Generally, Na deposition can allow equilibrium and controlled growth at low current densities in contrast to high current densities, which involve non-equilibrium and uncontrolled growth. ${ }^{179,180}$ For a perfect interphase, enhanced critical strain and high Young's modulus are essential to allow effective functioning at both low and high current densities. Nonuniform and uncontrolled growth due to volume expansion and contraction can be handled by high critical strain (ductile). Conversely, controlled and equilibrium growth can be obtained via a high Young's modulus (stiff), alleviating the generation of large dendrites. ${ }^{181}$ For rapid and smooth Na ion transport across the interphase, a low ionic diffusion barrier can be a crucial factor. For instance, existing SEI products such as NaF possess relatively large ionic diffusion barriers and $\mathrm{Na}_{2} \mathrm{O}$ is stiff but a very brittle ceramic product, whereas organic compounds possess high porosity but less stiffness. ${ }^{182,183}$ Consequently, the current $\mathrm{Na}$ anodes can only show stability at low current densities $(0.25$ to $\left.1 \mathrm{~mA} \mathrm{~cm}{ }^{-2}\right) .{ }^{160,184,185}$ Thus to circumvent this issue, Kumar et al. ${ }^{186}$ demonstrated a biphasic interphase (BPI) that was grown by reacting aqueous ammonia vapour with an $\mathrm{Na}$ metal anode, consisting of two chemically different phases $\left(\mathrm{NaNH}_{2}\right.$ and $\mathrm{NaOH}) \cdot \mathrm{NaNH}_{2}$ shows high ductility with high critical strain and $\mathrm{NaOH}$ possesses good stiffness with a high Young's modulus. Consequently, the BPI showed a smooth track with a low ion diffusion barrier, guiding the ions to dissolve and deposit uniformly. As a result, highly stable Na plating/stripping characteristics at high current densities (1-50 $\mathrm{mA} \mathrm{cm}{ }^{-2}$ ) and high areal capacities (1-10 $\mathrm{mA} \mathrm{h} \mathrm{cm}^{-2}$ ) were obtained. Unlike the solid-liquid approach, a solid-vapor approach was utilized to realize the formation of highly controlled metal-alloy interphases directly over the $\mathrm{Na}$ metal anode. The direct reaction of tintetrachloride $\left(\mathrm{SnCl}_{4}\right)$ vapor with $\mathrm{Na}$ metal led to the formation of localized metal-alloy interphases instantly. Due to the strong adhesion and enhanced Young's modulus of elasticity, the interphase could accommodate volume fluctuations. Conversely, a highly compact and uniform layer of metal-alloy ensures effective screening of the metal anode, while it provides improved ionic conductivity to the electrolyte ions. Besides exploring Sn-based alloys, it has been demonstrated that the reduction potential of the metal cation is a decisive factor in guaranteeing the formation of a metal alloy interphase. The reduction of the metal cation and further formation of an MAI with the Na anode due to the spontaneity of the reaction $(\Delta G<0)$ is supported by a high positive reduction potential with respect to Na. Another strategy to form a sodiophilic metal alloy interphase was proposed by Tang et $a{ }^{176}$ to enable efficient $\mathrm{Na}$ deposition and stripping. They compared the sodiophilicity of $\mathrm{Au}, \mathrm{Mo}, \mathrm{Cr}, \mathrm{Cu}, \mathrm{Sn}$ and $\mathrm{Sb}$ by electrochemical measurements and reported that only $\mathrm{Sb}, \mathrm{Au}$ and Sn formed an alloy with Na metal. ${ }^{187-189}$ They further highlighted the continuous alloying-dealloying resulted in pulverisation of the sodiophilic metal alloys, leading to the disappearance of the sodiophilic interphase. A technique for controlling the cut-off potential was employed and the Na-metal alloy interphase was bound by binders, as shown in Fig. 12c, resulting in an enhanced performance. Therefore, the formation of metal-alloy interphases can be helpful in improving the performance of alkali-metal anodes.

\section{Conclusion and future outlook}

The physiochemical engineering of the matrix is one of the key factors for the development of a stable and high sulfur-loaded sodium-sulfur battery system. Considering the fact that $\mathrm{Na}^{+}$ions are relatively bigger and sodium polysulfide are comparatively more corrosive than their $\mathrm{Li}$ analogue, the $\mathrm{RT}-\mathrm{Na} / \mathrm{S}$ battery is expected to suffer more severely than that of $\mathrm{Li}-\mathrm{S}$ battery system during its operation. With an increase sulfur loading or increased thickness of the cathode layer, several issues may become prominent, for instance, (1) a greater loading of active material in the electrode can result in material peel-off due to weak interparticle interaction, (2) as the thickness increases, the resistance increases due to the insulating nature of sulfur and (3) limited accessibility of electrolyte ions. ${ }^{190,191}$ Thus, various strategies have been developed to enhance the sulfur loading and mitigate polysulfide shuttling without adversely affecting the cell performance, and some of the important approaches were highlighted in the present review. Particularly, basic insight into the chemical binding, strategies for mesoscale assembly, unique architectures, and configurational innovation in the cathode were specific concerns. It is apparent from the literature that an improved sulfur loading can be realized in two ways. Firstly, through increased utilization of the sulfur cathode and mitigating the dissolution of the soluble discharge products during cycling. Secondly, infusing more and more sulfur into the matrix, and therefore, the matrix plays an important role in controlling the stability of RT-Na/S batteries. The primary focus of this review was to summarize the literature presenting novel ideas to alter the physiochemical properties of the matrix to enhance the sulfur loading. ${ }^{192}$ Although the fundamental properties of $\mathrm{Na}$ are largely different from $\mathrm{Li}$, the development of RT-Na/S batteries has also been assisted by the progress made in $\mathrm{Li}-\mathrm{S}$ batteries, and particularly the rational design of electrode materials.

Under the premise of a high S-loading, a few strategies can be proposed to ensure a high specific energy density: (1) use of modified and polar separators, (2) highly porous current collector architecture, (3) employing a compatible electrolyte system, (4) developing different functional moieties and judicious combination of different binder systems and (5) replacing sulfur with sulfur-rich composites, for example transition metal sulfides. These developments have been reported for different battery systems to enhance their performance and energy density, and it is likely that their contribution in RT-Na/S will also result in positive effects. 
In addition to fabricating suitable electrode architectures, an indirect approach is to develop modified separators for inhibiting the dissolution and simultaneously resolving the issue of the loss of the active materials. Lin et al. ${ }^{193}$ studied nickel cobaltite introduced into carbon nanofibres $\left(\mathrm{NiCo}_{2} \mathrm{O}_{4} / \mathrm{CNF}\right)$ as a modified separator to anchor the polysulfides and accelerate the conversion of long-chain to short-chain polysulfides through the Ni-S and Co-S bonding structure in an Li/S battery system. The modified separator demonstrated a well-defined interface with strong affinity towards polysulfides and rich polar nucleation sites, and thus could act as an accelerator and catalyze the conversion reactions. $\mathrm{NiCo}_{2} \mathrm{O}_{4} / \mathrm{CNF}$ could provide pathway for a fast ionic diffusion and electron mobility, resulting in a high S-loading of up to $7.9 \mathrm{mg} \mathrm{cm}^{-2}$.

Given that the design of a compatible electrolyte system is also important for achieving a stable system with higher safety, gel electrolytes are trailblazing technology for achieving a high S-content in cathode composites. To reach a S-loading of about $14 \mathrm{mg} \mathrm{cm}^{-2}$, a state-of-the art design of a highly elastic 3D-gel cathode was developed, which comprised an interconnected co-polymer skeleton (achieved through phase inversion strategy). ${ }^{194}$ The phase inversion strategy is a well-known universal technique for constructing a porous interconnected-polymeric network, and it can open up new pathways for the matrix to accommodate a high sulfur loading. ${ }^{195}$ During this process, three continuous phases merge, i.e., the $\mathrm{S} / \mathrm{C}$ composite, the pores phase and a polymeric phase are formed in one-pot simultaneously, leading to the development of an electronically conductive scaffold to promote conductive pathways. The tri-continuous structured matrix with an electron conductive network consists of interpenetrable macropores, which can favor electrolyte permeation and a high loading of sulfur. Gel electrolytes have also been fabricated in a similar fashion with an amorphous fluorinated co-polymer matrix with high ionic conductivity, rendering high flexibility and suppression of dendritic growth.

The binder is another important component, which is indispensable for achieving greater thickness of sulfur in the electrode material, and hence a high sulfur loading. However, the conventional way of using binders can limit the diffusion of electrolyte given that the binder can fill the spaces in the carbon matrix, thus resulting in a reduced sulfur loading in the electrode material. ${ }^{196}$ The premise of a high specific density can be ensured with a high sulfur loading. Recently, Shaibani and co-workers ${ }^{197}$ reported an expansion-tolerant architecture with a new approach to augment the number of active sites to accommodate a large fraction of active materials. Applying the bridging architecture mechanism, ${ }^{198}$ dispersion of a high modulus Na-CMC binder could be achieved by forming web-like bridging bonds between the neighbouring particles (without filling the voids of the matrix). A sulfur cathode with a sulfur loading as high as $15 \mathrm{mg} \mathrm{cm} \mathrm{cm}^{-2}$ could be achieved through the "bridging architecture technique." A new strategy of developing a high-loaded sulfur cathode system was recently proposed by Chen et $a{ }^{56}$ A 3D multifunctional flexible network composed of highly polar groups was developed as a binder for the elemental sulfur powder. The amino group-functionalized network encapsulated sulfur particles (AFG)@S and allowed a high sulfur loading of about $8 \mathrm{mg} \mathrm{cm}^{-2}$ without deteriorating the stability and cycle-life of the cell. Theoretical calculation predicted the high affinity of the $-\mathrm{NH}_{2}$ groups towards sulfur particles and dissolved lithium polysulfide. In addition, the 3D structure of the network offers abundant absorption or adsorption sites for polysulfides. Considering that sodium polysulfides are more soluble than lithium polysulfides, it is expected that they may access the absorption sites more easily compared to lithium polysulfides. Therefore, designing a functional multi-dimensional structure with highly polar adsorption sites can be pivotal in improving the utilization and loading of sulfur in sulfur cathodes for RT-Na/S batteries. Furthermore, Han and co-workers ${ }^{199}$ formulated the idea of a nucleophilic bi-functional binder with the ability to immobilize polysulfides within the carbon matrix for achieving a higher thickness of active materials. The combination of a maleate and amine group in a binder provides high efficacy for binding, besides chemical and mechanical stability. The bi-functional maleate poly-(ethylene glycol) (PEG) binder resulted in a high sulfur loading of about $12 \mathrm{mg} \mathrm{cm} \mathrm{cm}^{-2}$ with a sulfur content of $80 \mathrm{wt} \%$. Hencz et $a .^{200}$ illustrated the importance of a polymeric binder matrix in housing sulfur for providing the necessary interfacial interactions with an efficient interlocking mechanism.

Significant progress in the field of $\mathrm{RT} / \mathrm{Na}-\mathrm{S}$ batteries has been made in recent years; however, the viability of this technology still requires in-depth research to unveil the versatile aspects of the electrode materials. The physiochemical structure-property relationship needs to be developed in a more comprehensive manner to address the key challenges. There still exists a huge vacuum in this technology, which requires a better understanding of the conversion mechanisms through advanced characterization tools. Thus, continuous and innovative efforts are still required to further improve the performance of RT-Na/S batteries.

\section{Conflicts of interest}

There are no conflicts to declare.

\section{Acknowledgements}

Sungjemmenla, Chhail Bihari Soni, and Vineeth S. K., acknowledge the scholarship awarded by the Indian Institute of Technology Delhi (IIT Delhi). This work was financially supported by the IIT Delhi.

\section{References}

1 T. Kousksou, P. Bruel, A. Jamil, T. El Rhafiki and Y. Zeraouli, Sol. Energy Mater. Sol. Cells, 2014, 120, 59-80.

2 S. Choudhury, S. Wei, Y. Ozhabes, D. Gunceler, M. J. Zachman, Z. Tu, J. H. Shin, P. Nath, A. Agrawal and L. F. Kourkoutis, Nat. Commun., 2017, 8, 1-10.

3 B. Dunn, H. Kamath and J.-M. Tarascon, Science, 2011, 334, 928-935.

4 M. Armand and J.-M. Tarascon, Nature, 2008, 451, 652-657. 5 G. Zubi, R. Dufo-López, M. Carvalho and G. Pasaoglu, Renewable Sustainable Energy Rev., 2018, 89, 292-308. 
6 J. Liu, J. G. Zhang, Z. Yang, J. P. Lemmon, C. Imhoff, G. L. Graff, L. Li, J. Hu, C. Wang and J. Xiao, Adv. Funct. Mater., 2013, 23, 929-946.

7 F. Schipper, E. M. Erickson, C. Erk, J.-Y. Shin, F. F. Chesneau and D. Aurbach, J. Electrochem. Soc., 2016, 164, A6220.

8 A. Manthiram, J. Phys. Chem. Lett., 2011, 2, 176-184.

9 Y. Wang, D. Zhou, V. Palomares, D. Shanmukaraj, B. Sun, X. Tang, C. Wang, M. Armand, T. Rojo and G. Wang, Energy Environ. Sci., 2020, 13, 3848-3879.

10 R. De Silva, M. Jayaweera, V. Perera, I. Jayarathna and S. Rosa, Sri Lankan J. Phys., 2014, 15, 19-29.

11 Z. Wen, J. Cao, Z. Gu, X. Xu, F. Zhang and Z. Lin, Solid State Ionics, 2008, 179, 1697-1701.

12 K. Jung, H.-J. Heo, J.-H. Lee, Y.-C. Park and C.-Y. Kang, Corros. Sci., 2015, 98, 748-757.

13 J. T. Kummer and N. Weber, SAE Trans., 1968, 76, 1003-1028.

14 N. Kawakami, Y. Iijima, M. Fukuhara, M. Bando, Y. Sakanaka, K. Ogawa and T. Matsuda, Development and field experiences of stabilization system using 34MW NAS batteries for a 51MW wind farm, IEEE International Symposium on Industrial Electronics (ISIE2010), 2010, pp. 2371-2376.

15 S. Tewari and N. Mohan, IEEE Trans. Power Syst., 2012, 28, 532-541.

16 G. Nikiforidis, M. Van de Sanden and M. N. Tsampas, $R S C$ Adv., 2019, 9, 5649-5673.

17 V. Kumar, Y. Wang, A. Y. S. Eng, M.-F. Ng and Z. W. Seh, Cell Rep. Phys. Sci., 2020, 1, 100044.

18 Z. W. Seh, J. Sun, Y. Sun and Y. Cui, ACS Cent. Sci., 2015, 1, 449-455.

19 H. Ryu, T. Kim, K. Kim, J.-H. Ahn, T. Nam, G. Wang and H.-J. Ahn, J. Power Sources, 2011, 196, 5186-5190.

20 X. Yu and A. Manthiram, Chem. - Eur. J., 2015, 21, 4233-4237.

21 C.-W. Park, J.-H. Ahn, H.-S. Ryu, K.-W. Kim and H.-J. Ahn, Electrochem. Solid-State Lett., 2006, 9, A123.

22 J. Wang, J. Yang, Y. Nuli and R. Holze, Electrochem. Commun., 2007, 9, 31-34.

23 S. H. Chung and A. Manthiram, Adv. Mater., 2019, 31, 1901125.

24 D. Liu, Z. Li, X. Li, Z. Cheng, L. Yuan and Y. Huang, ChemPhysChem, 2019, 20, 3164-3176.

25 R. Dominko, A. Vizintin, G. Aquilanti, L. Stievano, M. J. Helen, A. R. Munnangi, M. Fichtner and I. Arcon, J. Electrochem. Soc., 2017, 165, A5014.

26 J. H. Lee, J. Kang, S.-W. Kim, W. Halim, M. W. Frey and Y. L. Joo, ACS Omega, 2018, 3, 16465-16471.

27 J. Liu, D. Lu, J. Zheng, P. Yan, B. Wang, X. Sun, Y. Shao, C. Wang, J. Xiao and J.-G. Zhang, ACS Appl. Mater. Interfaces, 2018, 10, 21965-21972.

28 S. Zhang, Y. Yao and Y. Yu, ACS Energy Lett., 2021, 6, 529-536.

29 X. Wang, T. Gao, F. Han, Z. Ma, Z. Zhang, J. Li and C. Wang, Nano Energy, 2016, 30, 700-708.

30 A. Ghosh, S. Shukla, M. Monisha, A. Kumar, B. Lochab and S. Mitra, ACS Energy Lett., 2017, 2, 2478-2485.

31 M. A. Pope and I. A. Aksay, Adv. Energy Mater., 2015, 5, 1500124.

32 D. Kumar, S. K. Rajouria, S. B. Kuhar and D. Kanchan, Solid State Ionics, 2017, 312, 8-16.
33 T. Li, J. Xu, C. Wang, W. Wu, D. Su and G. Wang, J. Alloys Compd., 2019, 792, 797-817.

34 Y. Wang, Y. Zhang, H. Cheng, Z. Ni, Y. Wang, G. Xia, X. Li and X. Zeng, Molecules, 2021, 26, 1535.

35 D. Kumar, D. Kanchan, S. Kumar and K. Mishra, Mater. Sci. Energy Technol., 2019, 2, 117-129.

36 N. Chawla and M. Safa, Electronics, 2019, 8, 1201.

37 H. B. Wu, S. Wei, L. Zhang, R. Xu, H. H. Hng and X. W. Lou, Chem. - Eur. J., 2013, 19, 10804-10808.

38 Y. V. Mikhaylik and J. R. Akridge, J. Electrochem. Soc., 2004, 151, A1969.

39 A. Manthiram, S. H. Chung and C. Zu, Adv. Mater., 2015, 27, 1980-2006.

40 P. Adelhelm, P. Hartmann, C. L. Bender, M. Busche, C. Eufinger and J. Janek, Beilstein J. Nanotechnol., 2015, 6, 1016-1055.

41 D. Liu, Z. Li, X. Li, Z. Cheng, L. Yuan and Y. Huang, ChemPhysChem, 2019, 20, 3164-3176.

42 Y. X. Wang, W. H. Lai, S. L. Chou, H. K. Liu and S. X. Dou, Adv. Mater., 2020, 32, 1903952.

43 Sungjemmenla, C. B. Soni and V. Kumar, Nanoscale Adv., 2021, 3, 1569-1581.

44 L. Wen, X. Wang, G. Q. Liu, H. Z. Luo, J. Liang and S. X. Dou, Surf. Innovations, 2017, 6, 13-18.

45 Z. Chen, Y. Qin, K. Amine and Y.-K. Sun, J. Mater. Chem., 2010, 20, 7606-7612.

46 F. Lecomte, J. Siepmann, M. Walther, R. J. MacRae and R. Bodmeier, Pharm. Res., 2004, 21, 882-890.

47 X. Yu and A. Manthiram, Matter, 2019, 1, 439-451.

48 Z. Wen, Y. Hu, X. Wu, J. Han and Z. Gu, Adv. Funct. Mater., 2013, 23, 1005-1018.

49 S. Lim, R. Lilly Thankamony, T. Yim, H. Chu, Y.-J. Kim, J. Mun and T.-H. Kim, ACS Appl. Mater. Interfaces, 2015, 7, 1401-1405.

50 W. Zhou, Y. Yu, H. Chen, F. J. DiSalvo and H. C. D. Abruña, J. Am. Chem. Soc., 2013, 135, 16736-16743.

51 Y. Fu and A. Manthiram, Chem. Mater., 2012, 24, 3081-3087.

52 H. Yi, T. Lan, Y. Yang, H. Zeng, T. Zhang, T. Tang, C. Wang and Y. Deng, Energy Storage Mater., 2019, 21, 61-68.

53 M. Ling, L. Zhang, T. Zheng, J. Feng, J. Guo, L. Mai and G. Liu, Nano Energy, 2017, 38, 82-90.

54 A. Y. S. Eng, D.-T. Nguyen, V. Kumar, G. S. Subramanian, M.-F. Ng and Z. W. Seh, J. Mater. Chem. A, 2020, 8, 22983-22997.

55 S.-L. Chou, Y. Pan, J.-Z. Wang, H.-K. Liu and S.-X. Dou, Phys. Chem. Chem. Phys., 2014, 16, 20347-20359.

56 W. Chen, T. Qian, J. Xiong, N. Xu, X. Liu, J. Liu, J. Zhou, $\mathrm{X}$. Shen, T. Yang and Y. Chen, Adv. Mater., 2017, 29, 1605160.

57 J. Liu, D. G. Galpaya, L. Yan, M. Sun, Z. Lin, C. Yan, C. Liang and S. Zhang, Energy Environ. Sci., 2017, 10, 750-755.

58 S. Waluś, G. Offer, I. Hunt, Y. Patel, T. Stockley, J. Williams and R. Purkayastha, Energy Storage Mater., 2018, 10, 233-245.

59 G. Rong-Nan and H. Wei-Qiang, J. Inorg. Mater., 2019, 34, 1021-1029.

60 Y. Jiao, W. Chen, T. Lei, L. Dai, B. Chen, C. Wu and J. Xiong, Nanoscale Res. Lett., 2017, 12, 1-8. 
61 A. Ghosh, A. Kumar, A. Roy, M. R. Panda, M. Kar, D. R. MacFarlane and S. Mitra, ACS Appl. Mater. Interfaces, 2019, 11, 14101-14109.

62 T. Wu, M. Jing, L. Yang, G. Zou, H. Hou, Y. Zhang, Y. Zhang, X. Cao and X. Ji, Adv. Energy Mater., 2019, 9, 1803478.

63 K. Chen, H. Li, Y. Xu, K. Liu, H. Li, X. Xu, X. Qiu and M. Liu, Nanoscale, 2019, 11, 5967-5973.

64 J. Yan, W. Li, R. Wang, P. Feng, M. Jiang, J. Han, S. Cao, Z. Zhang, K. Wang and K. Jiang, ACS Energy Lett., 2020, 5, 1307-1315.

65 C. Ling and F. Mizuno, Phys. Chem. Chem. Phys., 2014, 16, 10419-10424.

66 F. Wu, R. Dong, Y. Bai, Y. Li, G. Chen, Z. Wang and C. Wu, ACS Appl. Mater. Interfaces, 2018, 10, 21335-21342.

67 X. Wang, S. Wang, K. Shen, S. He, X. Hou and F. Chen, J. Mater. Chem. A, 2020, 8, 4007-4016.

68 Y. Fang, X. Y. Yu and X. W. Lou, Angew. Chem., 2019, 131, 7826-7830.

69 K. Zhang, F. Zhang, H. Pan, J. Yu, L. Wang, D. Wang, L. Wang, G. Hu, J. Zhang and Y. Qian, Electrochim. Acta, 2020, 354, 136648.

70 B.-W. Zhang, T. Sheng, Y.-D. Liu, Y.-X. Wang, L. Zhang, W.-H. Lai, L. Wang, J. Yang, Q.-F. Gu and S.-L. Chou, Nat. Commun., 2018, 9, 1-11.

71 N. Wang, Y. Wang, Z. Bai, Z. Fang, X. Zhang, Z. Xu, Y. Ding, X. Xu, Y. Du and S. Dou, Energy Environ. Sci., 2020, 13, 562-570.

72 S. Li, Z. Zeng, J. Yang, Z. Han, W. Hu, L. Wang, J. Ma, B. Shan and J. Xie, ACS Appl. Energy Mater., 2019, 2, 2956-2964.

73 S. Zheng, P. Han, Z. Han, P. Li, H. Zhang and J. Yang, Adv. Energy Mater., 2014, 4, 1400226.

74 J. Zhu, A. Abdelkader, D. Demko, L. Deng, P. Zhang, T. He, Y. Wang and L. Huang, Molecules, 2020, 25, 1585.

75 S. Wei, S. Xu, A. Agrawral, S. Choudhury, Y. Lu, Z. Tu, L. Ma and L. A. Archer, Nat. Commun., 2016, 7, 1-10.

76 D. Kumar, D. Kanchan, S. Kumar and K. Mishra, Mater. Sci. Energy Technol., 2019, 2, 117-129.

$77 \mathrm{X} . \mathrm{Yu}$ and A. Manthiram, J. Phys. Chem. Lett., 2014, 5, 1943-1947.

78 M. Wang, W. Wang, A. Wang, K. Yuan, L. Miao, X. Zhang, Y. Huang, Z. Yu and J. Qiu, Chem. Commun., 2013, 49, 10263-10265.

79 S. Wei, L. Ma, K. E. Hendrickson, Z. Tu and L. A. Archer, J. Am. Chem. Soc., 2015, 137, 12143-12152.

80 X. Wang, X. Hao, Y. Xia, Y. Liang, X. Xia and J. Tu, J. Membr. Sci., 2019, 582, 37-47.

81 J. Ye, F. He, J. Nie, Y. Cao, H. Yang and X. Ai, J. Mater. Chem. A, 2015, 3, 7406-7412.

82 I. Kim, C. H. Kim, S. H. Choi, J.-P. Ahn, J.-H. Ahn, K.-W. Kim, E. J. Cairns and H.-J. Ahn, J. Power Sources, 2016, 307, 31-37.

83 T. H. Hwang, D. S. Jung, J.-S. Kim, B. G. Kim and J. W. Choi, Nano Lett., 2013, 13, 4532-4538.

84 Z. Li, J. Zhang, Y. Lu and X. W. D. Lou, Sci. Adv., 2018, 4, eaat1687.

85 D. Ma, Y. Li, J. Yang, H. Mi, S. Luo, L. Deng, C. Yan, M. Rauf, P. Zhang and X. Sun, Adv. Funct. Mater., 2018, 28, 1705537.
86 S. Xin, Y. X. Yin, Y. G. Guo and L. J. Wan, Adv. Mater., 2014, 26, 1261-1265.

87 M. Shobana, J. Alloys Compd., 2019, 802, 477-487.

88 C. Ye, D. Chao, J. Shan, H. Li, K. Davey and S.-Z. Qiao, Matter, 2020, 2, 323-344.

89 W. G. Chong, J. Q. Huang, Z. L. Xu, X. Qin, X. Wang and J. K. Kim, Adv. Funct. Mater., 2017, 27, 1604815.

90 L. Hu, Y. Lu, T. Zhang, T. Huang, Y. Zhu and Y. Qian, ACS Appl. Mater. Interfaces, 2017, 9, 13813-13818.

91 Z. Zhang, L. L. Kong, S. Liu, G. R. Li and X. P. Gao, Adv. Energy Mater., 2017, 7, 1602543.

92 L. Qie and A. J. A. M. Manthiram, Adv. Mater., 2015, 27, 1694-1700.

93 Q. Pang, X. Liang, C. Y. Kwok, J. Kulisch and L. F. Nazar, Adv. Energy Mater., 2017, 7, 1601630.

94 Y. Ma, H. Zhang, B. Wu, M. Wang, X. Li and H. Zhang, Sci. Rep., 2015, 5, 14949.

95 G. Zhou, L. Li, C. Ma, S. Wang, Y. Shi, N. Koratkar, W. Ren, F. Li and H.-M. Cheng, Nano Energy, 2015, 11, 356-365.

96 M. Hagen, S. Dörfler, H. Althues, J. Tübke, M. Hoffmann, S. Kaskel and K. Pinkwart, J. Power Sources, 2012, 213, 239-248.

97 I. Kim, J.-Y. Park, C. H. Kim, J.-W. Park, J.-P. Ahn, J.-H. Ahn, K.-W. Kim and H.-J. Ahn, J. Power Sources, 2016, 301, 332-337.

98 X. Hu, Y. Ni, C. Wang, H. Wang, E. Matios, J. Chen and W. Li, Cell Rep. Phys. Sci., 2020, 1, 100015.

99 H. Ye, L. Ma, Y. Zhou, L. Wang, N. Han, F. Zhao, J. Deng, T. Wu, Y. Li and J. Lu, Proc. Natl. Acad. Sci. U. S. A., 2017, 114, 13091-13096.

100 M. Sajjad, T. Hussain, N. Singh and J. A. Larsson, Langmuir, 2020, 36, 13104-13111.

101 L. Sun, M. Li, Y. Jiang, W. Kong, K. Jiang, J. Wang and S. J. N. L. Fan, Nano Lett., 2014, 14, 4044-4049.

102 Z. Yuan, H.-J. Peng, J.-Q. Huang, X.-Y. Liu, D.-W. Wang, X.-B. Cheng and Q. Zhang, Adv. Funct. Mater., 2014, 24, 6105-6112.

103 X. Xu, D. Zhou, X. Qin, K. Lin, F. Kang, B. Li, D. Shanmukaraj, T. Rojo, M. Armand and G. Wang, Nat. Commun., 2018, 9, 3870.

104 D. Kumar, Solid State Ionics, 2018, 318, 65-70.

105 X. Bian, Y. Gao, Q. Fu, S. Indris, Y. Ju, Y. Meng, F. Du, N. Bramnik, H. Ehrenberg and Y. Wei, J. Mater. Chem. A, 2017, 5, 600-608.

106 X. Liu, J. Q. Huang, Q. Zhang and L. Mai, Adv. Mater., 2017, 29, 1601759.

107 Y. Xu, A. Sumboja, A. Groves, T. Ashton, Y. Zong and J. A. Darr, $R S C$ Adv., 2020, 10, 41871-41882.

108 J. He, Y. Chen and A. Manthiram, iScience, 2018, 4, 36-43. 109 T. Zhu, X. Dong, Y. Liu, Y.-G. Wang, C. Wang and Y.-Y. Xia, ACS Appl. Energy Mater., 2019, 2, 5263-5271.

110 Q. Ma, G. Du, B. Guo, W. Tang, Y. Li, M. Xu and C. Li, Chem. Eng. J., 2020, 388, 124210.

111 Q. Lu, X. Wang, J. Cao, C. Chen, K. Chen, Z. Zhao, Z. Niu and J. Chen, Energy Storage Mater., 2017, 8, 77-84.

112 I. Kim, C. Kim, H. Kim, K.-W. Kim, J.-H. Ahn and H.-J. Ahn, J. Nanosci. Nanotechnol., 2018, 18, 6524-6527. 
113 Q. Guo, S. Li, X. Liu, H. Lu, X. Chang, H. Zhang, X. Zhu, Q. Xia, C. Yan and H. Xia, Adv. Sci., 2020, 7, 1903246.

114 R. Fang, S. Zhao, P. Hou, M. Cheng, S. Wang, H. M. Cheng, C. Liu and F. Li, Adv. Mater., 2016, 28, 3374-3382.

115 H. Nara, T. Yokoshima, H. Mikuriya, S. Tsuda, T. Momma and T. Osaka, J. Electrochem. Soc., 2016, 164, A5026.

116 M. K. Aslam, I. D. Seymour, N. Katyal, S. Li, T. Yang, S.-J. Bao, G. Henkelman and M. Xu, Nat. Commun., 2020, 11, 1-11.

117 R. Carter, L. Oakes, A. Douglas, N. Muralidharan, A. P. Cohn and C. L. Pint, Nano Lett., 2017, 17, 1863-1869.

118 Y.-X. Wang, J. Yang, W. Lai, S.-L. Chou, Q.-F. Gu, H. K. Liu, D. Zhao and S. X. Dou, J. Am. Chem. Soc., 2016, 138, 16576-16579.

119 H. J. Peng, J. Q. Huang, X. B. Cheng and Q. Zhang, Adv. Energy Mater., 2017, 7, 1700260.

120 Y. Zhang, J. Ren, D. Wang, C. Zhang, F. Yin, A. Mukanova and Z. Bakenov, ChemElectroChem, 2018, 5, 1591-1598.

121 S. Rehman, K. Khan, Y. Zhao and Y. Hou, J. Mater. Chem. A, 2017, 5, 3014-3038.

122 S. Rehman, K. Khan, Y. Zhao and Y. Hou, J. Mater. Chem. A, 2017, 5, 3014-3038.

123 L. He, W. C. Li, S. Xu and A. H. Lu, Chem. - Eur. J., 2019, 25, 3209-3218.

124 R. Zhao, Z. Liang, R. Zou and Q. Xu, Joule, 2018, 2, 2235-2259.

125 X. Li, S. Zheng, L. Jin, Y. Li, P. Geng, H. Xue, H. Pang and Q. Xu, Adv. Energy Mater., 2018, 8, 1800716.

126 Z. Wang, H. Tao and Y. Yue, ChemElectroChem, 2019, 6, 5358-5374.

127 R. Chen, T. Zhao, T. Tian, S. Cao, P. R. Coxon, K. Xi, D. Fairen-Jimenez, R. Vasant Kumar and A. K. Cheetham, APL Mater., 2014, 2, 124109.

128 Q. Wu, X. Zhou, J. Xu, F. Cao and C. Li, J. Energy Chem., 2019, 38, 94-113.

129 J. Xu, W. Zhang, Y. Chen, H. Fan, D. Su and G. Wang, J. Mater. Chem. A, 2018, 6, 2797-2807.

130 A. E. Baumann, D. A. Burns, B. Liu and V. S. Thoi, Commun. Chem., 2019, 2, 1-14.

131 J. Zhou, R. Li, X. Fan, Y. Chen, R. Han, W. Li, J. Zheng, B. Wang and X. Li, Energy Environ. Sci., 2014, 7, 2715-2724.

132 L. Zhang, B. Zhang, Y. Dou, Y. Wang, M. Al-Mamun, X. Hu and H. Liu, ACS Appl. Mater. Interfaces, 2018, 10, 20422-20428.

133 Y.-M. Chen, W. Liang, S. Li, F. Zou, S. M. Bhaway, Z. Qiang, M. Gao, B. D. Vogt and Y. Zhu, J. Mater. Chem. A, 2016, 4, 12471-12478.

134 D.-J. Lee, J.-W. Park, I. Hasa, Y.-K. Sun, B. Scrosati and J. Hassoun, J. Mater. Chem. A, 2013, 1, 5256-5261.

135 G. Xia, L. Zhang, X. Chen, Y. Huang, D. Sun, F. Fang, Z. Guo and X. Yu, Energy Storage Mater., 2018, 14, 314-323.

136 K. Chen, Z. Sun, R. Fang, Y. Shi, H. M. Cheng and F. Li, Adv. Funct. Mater., 2018, 28, 1707592.

137 M. Zhang, C. Yu, C. Zhao, X. Song, X. Han, S. Liu, C. Hao and J. Qiu, Energy Storage Mater., 2016, 5, 223-229.

138 R. Yan, M. Oschatz and F. Wu, Carbon, 2020, 161, 162-168. 139 Z. Yan, J. Xiao, W. Lai, L. Wang, F. Gebert, Y. Wang, Q. Gu, H. Liu, S.-L. Chou and H. Liu, Nat. Commun., 2019, 10, 1-8.
140 B. Guo, W. Du, T. Yang, J. Deng, D. Liu, Y. Qi, J. Jiang, S. J. Bao and M. Xu, Adv. Sci., 2020, 7, 1902617.

141 Y. L. Ding, P. Kopold, K. Hahn, P. A. van Aken, J. Maier and Y. Yu, Adv. Funct. Mater., 2016, 26, 1112-1119.

142 J. Song, M. L. Gordin, T. Xu, S. Chen, Z. Yu, H. Sohn, J. Lu, Y. Ren, Y. Duan and D. Wang, Angew. Chem., 2015, 127, 4399-4403.

143 W. Ren, W. Ma, S. Zhang and B. Tang, Chem. Eng. J., 2018, 341, 441-449.

144 Q. Li, J. Guo, J. Zhao, C. Wang and F. Yan, Nanoscale, 2019, 11, 647-655.

145 F. Xiao, X. Yang, H. Wang, J. Xu, Y. Liu, D. Y. Yu and A. L. Rogach, Adv. Energy Mater., 2020, 10, 2000931.

146 Y. Hao, X. Li, X. Sun and C. Wang, ChemistrySelect, 2017, 2, 9425-9432.

147 Z. Qiang, Y.-M. Chen, Y. Xia, W. Liang, Y. Zhu and B. D. Vogt, Nano Energy, 2017, 32, 59-66.

148 M. L. Meyerson, P. E. Papa, J. A. Weeks, A. G. Paul-Orecchio, A. Heller and C. B. Mullins, ACS Appl. Energy Mater., 2020, 3, 6121-6126.

149 I. Bauer, M. Kohl, H. Althues and S. Kaskel, Chem. Commun., 2014, 50, 3208-3210.

150 S. Wenzel, H. Metelmann, C. Raiß, A. K. Dürr, J. Janek and P. Adelhelm, J. Power Sources, 2013, 243, 758-765.

151 X. Yu and A. Manthiram, J. Phys. Chem. C, 2014, 118, 22952-22959.

152 X. Yu and A. Manthiram, Chem. - Eur. J., 2015, 21, 4233-4237. 153 X. Yu and A. Manthiram, Chem. Mater., 2016, 28, 896-905.

154 L. M. Bloi, J. Pampel, S. Dörfler, H. Althues and S. Kaskel, Adv. Energy Mater., 2020, 10, 1903245.

155 A. Kumar, A. Ghosh, A. Roy, M. R. Panda, M. Forsyth, D. R. MacFarlane and S. Mitra, Energy Storage Mater., 2019, 20, 196-202.

156 B. Sun, P. Xiong, U. Maitra, D. Langsdorf, K. Yan, C. Wang, J. Janek, D. Schröder and G. Wang, Adv. Mater., 2020, 32, 1903891.

157 Y. Zhao, K. R. Adair and X. Sun, Energy Environ. Sci., 2018, 11, 2673-2695.

158 X. Zheng, C. Bommier, W. Luo, L. Jiang, Y. Hao and Y. Huang, Energy Storage Mater., 2019, 16, 6-23.

159 X. Zheng, H. Fu, C. Hu, H. Xu, Y. Huang, J. Wen, H. Sun, W. Luo and Y. Huang, J. Phys. Chem. Lett., 2019, 10, 707-714.

160 H. Wang, C. Wang, E. Matios and W. Li, Nano Lett., 2017, 17, 6808-6815.

161 X. Chen, X. Shen, B. Li, H. J. Peng, X. B. Cheng, B. Q. Li, X. Q. Zhang, J. Q. Huang and Q. Zhang, Angew. Chem., Int. Ed., 2018, 57, 734-737.

162 J. Luo, C. Wang, H. Wang, X. Hu, E. Matios, X. Lu, W. Zhang, X. Tao and W. Li, Adv. Funct. Mater., 2019, 29, 1805946.

163 F. Wu, J. Zhou, R. Luo, Y. Huang, Y. Mei, M. Xie and R. Chen, Energy Storage Mater., 2019, 22, 376-383.

164 Y. Gu, W.-W. Wang, Y.-J. Li, Q.-H. Wu, S. Tang, J.-W. Yan, M.-S. Zheng, D.-Y. Wu, C.-H. Fan and W.-Q. Hu, Nat. Commun., 2018, 9, 1-9.

165 S. Wang, Y. Jie, Z. Sun, W. Cai, Y. Chen, F. Huang, Y. Liu, X. Li, R. Du and R. Cao, ACS Appl. Energy Mater., 2020, 3, 8688-8694. 
166 Y. Zhao, X. Yang, L. Y. Kuo, P. Kaghazchi, Q. Sun, J. Liang, B. Wang, A. Lushington, R. Li and H. Zhang, Small, 2018, 14, 1703717.

167 K. Karuppasamy, J. Theerthagiri, D. Vikraman, C.-J. Yim, S. Hussain, R. Sharma, T. Maiyalagan, J. Qin and H.-S. Kim, Polymers, 2020, 12, 918.

168 S. S. Zhang, J. Electrochem. Soc., 2013, 160, A1421.

169 C. Vidal-Abarca, P. Lavela, J. L. Tirado, A. V. Chadwick, M. Alfredsson and E. Kelder, J. Power Sources, 2012, 197, 314-318.

170 L. Wang, T. Wang, L. Peng, Y. Wang, M. Zhang, J. Zhou, M. Chen, J. Cao, H. Fei and X. Duan, Natl. Sci. Rev., 2021, DOI: $10.1093 / \mathrm{nsr} / \mathrm{nwab050.}$

171 E. Matios, H. Wang, C. Wang and W. Li, Ind. Eng. Chem. Res., 2019, 58, 9758-9780.

172 M. S. Syali, D. Kumar, K. Mishra and D. Kanchan, Energy Storage Mater., 2020, 31, 352-372.

173 A. Y. S. Eng, V. Kumar, Y. Zhang, J. Luo, W. Wang, Y. Sun, W. Li and Z. W. Seh, Adv. Energy Mater., 2021, 2003493.

174 X. Zheng, H. Fu, C. Hu, H. Xu, Y. Huang, J. Wen, H. Sun, W. Luo and Y. Huang, J. Phys. Chem. Lett., 2019, 10, 707-714.

175 V. Kumar, A. Y. S. Eng, Y. Wang, D.-T. Nguyen, M.-F. Ng and Z. W. Seh, Energy Storage Mater., 2020, 29, 1-8.

176 S. Tang, Y. Y. Zhang, X. G. Zhang, J. T. Li, X. Y. Wang, J. W. Yan, D. Y. Wu, M. S. Zheng, Q. F. Dong and B. W. Mao, Adv. Mater., 2019, 31, 1807495.

177 B. Zhang, R. Dugas, G. Rousse, P. Rozier, A. M. Abakumov and J.-M. Tarascon, Nat. Commun., 2016, 7, 1-9.

178 Z. Li, J. Ding and D. Mitlin, Acc. Chem. Res., 2015, 48, 1657-1665.

179 Y. Liu, Y. Zhu and Y. Cui, Nat. Energy, 2019, 4, 540-550.

180 B. L. Mehdi, J. Qian, E. Nasybulin, C. Park, D. A. Welch, R. Faller, H. Mehta, W. A. Henderson, W. Xu, C. M. Wang, J. E. Evans, J. Liu, J. G. Zhang, K. T. Mueller and N. D. Browning, Nano Lett., 2015, 15, 2168-2173.

181 H. Tian, Z. W. Seh, K. Yan, Z. Fu, P. Tang, Y. Lu, R. Zhang, D. Legut, Y. Cui and Q. Zhang, Adv. Energy Mater., 2017, 7, 1602528.

182 S. Choudhury, S. Wei, Y. Ozhabes, D. Gunceler, M. J. Zachman, Z. Tu, J. H. Shin, P. Nath, A. Agrawal, L. F. Kourkoutis, T. A. Arias and L. A. Archer, Nat. Commun., 2017, 8, 898.
183 Z. W. Seh, J. Sun, Y. Sun and Y. Cui, ACS Cent. Sci., 2015, 1, 449-455.

184 Y.-J. Kim, H. Lee, H. Noh, J. Lee, S. Kim, M.-H. Ryou, Y. M. Lee and H.-T. Kim, ACS Appl. Mater. Interfaces, 2017, 9, 6000-6006.

185 W. Luo, C. F. Lin, O. Zhao, M. Noked, Y. Zhang, G. W. Rubloff and L. Hu, Adv. Energy Mater., 2017, 7, 1601526.

186 V. Kumar, Y. Wang, A. Y. S. Eng, M.-F. Ng and Z. W. Seh, Cell Rep. Phys. Sci., 2020, 1, 100044.

187 W. Luo, F. Shen, C. Bommier, H. Zhu, X. Ji and L. Hu, Acc. Chem. Res., 2016, 49, 231-240.

188 M. Lao, Y. Zhang, W. Luo, Q. Yan, W. Sun and S. X. Dou, Adv. Mater., 2017, 29, 1700622.

189 J. M. Stratford, M. Mayo, P. K. Allan, O. Pecher, O. J. Borkiewicz, K. M. Wiaderek, K. W. Chapman, C. J. Pickard, A. J. Morris and C. P. Grey, J. Am. Chem. Soc., 2017, 139, 7273-7286.

190 Q. Lu, X. Wang, J. Cao, C. Chen, K. Chen, Z. Zhao, Z. Niu and J. Chen, Energy Storage Mater., 2017, 8, 77-84.

191 J. Brückner, S. Thieme, H. T. Grossmann, S. Dörfler, H. Althues and S. Kaskel, J. Power Sources, 2014, 268, 82-87.

192 L. Zhu, W. Zhu, X.-B. Cheng, J.-Q. Huang, H.-J. Peng, S.-H. Yang and Q. Zhang, Carbon, 2014, 75, 161-168.

193 J.-X. Lin, X.-M. Qu, X.-H. Wu, J. Peng, S.-Y. Zhou, J.-T. Li, Y. Zhou, Y.-X. Mo, M.-J. Ding and L. Huang, ACS Sustainable Chem. Eng., 2021, 9, 1804-1813.

194 W. Yan, J. Wei, T. Chen, L. Duan, L. Wang, X. Xue, R. Chen, W. Kong, H. Lin and C. Li, Nano Energy, 2021, 80, 105510.

195 X. Yang, Y. Chen, M. Wang, H. Zhang, X. Li and H. Zhang, Adv. Funct. Mater., 2016, 26, 8427-8434.

196 M. Hagen, D. Hanselmann, K. Ahlbrecht, R. Maça, D. Gerber and J. Tübke, Adv. Energy Mater., 2015, 5, 1401986.

197 M. Shaibani, M. S. Mirshekarloo, R. Singh, C. D. Easton, M. D. Cooray, N. Eshraghi, T. Abendroth, S. Dörfler, H. Althues and S. Kaskel, Sci. Adv., 2020, 6, eaay2757.

198 H. Kokubo, S. Nakamura and H. Sunada, Chem. Pharm. Bull., 1995, 43, 1402-1406.

199 P. Han, S.-H. Chung, C.-H. Chang and A. Manthiram, ACS Appl. Mater. Interfaces, 2019, 11, 17393-17399.

200 L. Hencz, H. Chen, H. Y. Ling, Y. Wang, C. Lai, H. Zhao and S. Zhang, Nanomicro Lett., 2019, 11, 1-44. 